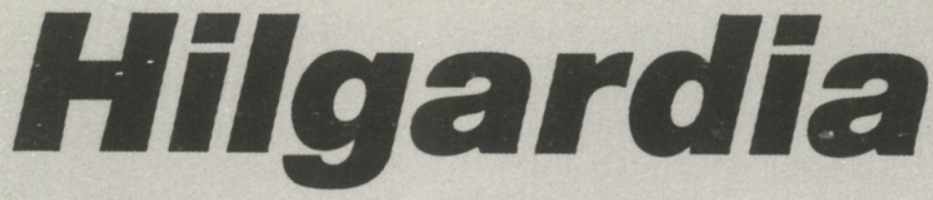

A. JOURNAL OF AGRICULTURAL SCIENCE PUBLISHED BY THE CALIFORNIA AGRICULTURAL EXPERIMENT STATION

\title{
The White-Tailed Deer of North Manitou Island
}

David J. Case and Dale R. McCullough

\author{
End of Volume
}




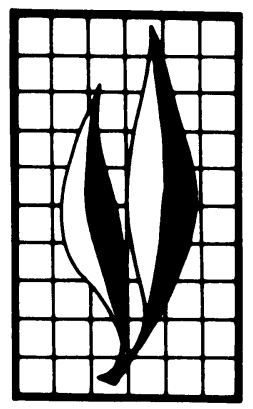

\section{ABSTRACT}

The white-tailed deer population on North Manitou Island, Michigan, was studied between June 1980 and May 1982. The National Park Service acquired the island in 1980 , ending many years of deer hunting and winter feeding administered by the previous owners. A heavy dieoff in the winter of 1977-78 was the result of cessation of winter feeding by the private owners. Winter mortality was low in the following years as the severely reduced population began to increase. The population increased by an estimated 66 percent in 1980 and 59 percent in 1981 to a pre-winter population estimated at 2,080 deer. In a second major dieoff in the winter of 1981-82, an estimated 76 percent of the population died. Fawns were most susceptible to winter mortality, and males were more susceptible than females among adults. Favorable spring-through-fall foods, including grasses, forbs, fruits, and an unusual food, a fish (the alewife), many of which die in annual cycles in Lake Michigan, support high population productivity. However, woody browse has been largely eliminated by previous deer browsing, with the exception of American beech, an unpalatable species. The lack of quality woody browse for winter food and the lack of winter thermal cover make the population highly susceptible to winter mortality. The combination of favorable habitat from spring through fall and poor habitat in winter in a region with severe winter conditions can be expected to continue the historic pattern of rapid population increases followed by massive winter losses. This pattern can be broken. Hunting can control deer population numbers and allow regeneration of a more natural mix of woody species.

\section{THE AUTHORS:}

David J. Case, former Graduate Student in the School of Natural Resources, University of Michigan, Ann Arbor, is now President of D. J. Case and Associates of Mishawaka, Indiana.

Dale R. McCullough is Professor of Wildlife Biology in the Department of Forestry and Resource Management and Research Conservationist in the Museum of Vertebrate Zoology, University of California, Berkeley. 


\section{The White-Tailed Deer of North Manitou Island ${ }^{1}$}

\section{INTRODUCTION}

\section{Background}

SLeEPing Bear dunes National lakeshore was created in October 1970 by Public Law 91-479. Included in the Lakeshore was North Manitou Island (NMI), a $60-\mathrm{km}^{2}$, privately owned island in Lake Michigan. In addition to many outstanding natural features, NMI had an introduced population of white-tailed deer (Odocoileus virginianus) that had been maintained at high levels by artificial feeding for many years.

Although the white-tailed deer has been the subject of many detailed studies (e.g., Nelson and Mech 1981; Woolf and Harder 1979; McCullough 1979; Hirth 1977; Teer, Thomas, and Walker 1965), public agencies charged with the management of white-tailed deer continue to become involved in controversies. Therefore, before purchase of NMI, the National Park Service decided to conduct a study of the NMI deer herd. This decision was prompted by recent deer management problems the Park Service had experienced with the Beaver Basin deer herd in Pictured Rocks National Lakeshore on Michigan's Upper Peninsula. At Pictured Rocks, the Park Service decided in 1975 to terminate the winter feeding program that had been conducted for many years, recommending that the deer be reduced by hunting (Robinson et al. 1982). Local sports enthusiasts strongly objected to both proposals, and the resultant controversy eventually involved local, state, and national resource agencies and politicians.

The objectives of this study were to obtain information on the population ecology and habitat relationships of the deer herd on NMI. This information would document the effects of prolonged deer overpopulation and winter mortality on the sex structure, age structure, reproduction, and dynamics of the deer herd and on the reproduction and composition of island vegetation. Using this baseline information on the deer herd and habitat, the Park Service could then make scientifically based management decisions and present these decisions to the public.

\section{Description of the Study Area}

North Manitou Island is a 5,968-ha island located at $45^{\circ} 07^{\prime}$ north latitude and $86^{\circ} 01^{\prime}$ east longitude in northern Lake Michigan (fig. 1). The longest north-south distance on the island is $11.8 \mathrm{~km}$ and the longest east-west distance is $6.9 \mathrm{~km}$. Pyramid Point is the nearest mainland point, $11.2 \mathrm{~km}$ to the southeast. North Manitou Island is the second largest island in a 14-island archipelago. South Manitou Island is $6.0 \mathrm{~km}$ to the southwest and South Fox Island is $27.2 \mathrm{~km}$ to the north.

Litigation between the Park Service and the island's owners over the purchase price began in 1978 and was in progress at the time of this study. Public use of the island was

${ }^{1}$ Accepted for publication July 23, 1987. 




Fig. 1. Location of North Manitou Island, Michigan, and habitat type map, 1981. 
restricted, and only two people other than the researchers were present on the island during the study.

The island is a glacial moraine and outwash plain created about 12,000 years ago by glaciers (Weber 1973). Topography is nearly level, with gently rolling hills on the east and central portions of the island and very steep hills and sand dune bluffs on the northwest and south portions. Elevations range from $183 \mathrm{~m}$ to $305 \mathrm{~m}$ above sea level. Soils include well-drained loamy sands, sandy loams, and sands with a small amount of poorly drained muck (Weber 1973).

Records from Traverse City, the nearest official weather station, indicate warm, mild summers and cold, snowy winters, with a frost-free period from 20 May to 6 October. Average rainfall is about $76 \mathrm{~cm}$ per year, and snowfall averages $185 \mathrm{~cm}$ per year (Rogers 1973).

Most of the timber on NMI was logged in the late 1800s and early 1900s (Hatt et al. 1948). The forested areas have since matured and have been logged again periodically since the 1940 s. In the 1960 s, the owners apparently instituted a selective-cut/shelterwood timber management scheme.

Current plant communities (fig. 1) typify those of the northern hardwood forest region, but show severe effects from prolonged overbrowsing by deer. Northern hardwood forests cover 82.7 percent of the island (table 1). Thirty percent of the northern hardwood forest ( 25.0 percent of the island) has been selectively logged in the past 20 years. Dominant tree species in the northern hardwood forest include American beech (Fagus grandifolia), sugar maple (Acer saccharum), and wild cherry (Prunus serotina). Less abundant tree species include yellow birch (Betula alleghaniensis), paper birch (Betula papyrifera), eastern hemlock (Tsuga canadensis), ash (Fraxinus spp.), eastern hophornbeam (Ostrya virginiana), mountain maple (Acer spicatum), and American basswood (Tilia americana).

Understory vegetation in the mature forests is sparse due to heavy deer browsing. Beech is the dominant species in selective-cut areas. American elder (Sambucus canadensis) and Rubus spp. are occasionally found in locations protected from deer browsing.

Aspen (Populus spp.) and paper birch are the dominant tree species in the aspenbirch habitat type, with varying amounts of beech, sugar maple, and wild cherry. The

TABLE 1. HABITAT TYPES ON NORTH MANITOU ISLAND, AS DETERMINED FROM AERIAL PHOTOS AND FIELD RECONNAISSANCE

\begin{tabular}{lcc}
\hline \hline Habitat type & Area & Percentage of island \\
\hline & $b a$ & \\
Northern hardwoods & 3,445 & 57.7 \\
Selective-cut northern hardwoods & 1,492 & 25.0 \\
Aspen-birch & 293 & 4.9 \\
Conifer & 125 & 2.1 \\
Open field & 308 & 5.1 \\
Marsh and lake & 117 & 2.0 \\
Sand dune and beach & 188 & 3.2 \\
\cline { 2 - 2 } Total & 5,968 & 100.0 \\
\hline
\end{tabular}


aspen-birch type makes up a relatively small ( 4.9 percent), poorly defined area, and its understory vegetation is similar to that of the uncut northern hardwood forest type.

The conifer type covers 2.1 percent of the island and varies in dominant tree species from area to area. On the southeast shoreline (fig. 1), red pine (Pinus resinosa) and white pine (Pinus strobus) dominate, with lesser amounts of eastern hemlock and balsam fir (Abies balsamea). Northern white cedar (Thuja occidentalis) dominates in moister habitats and areas along the Lake Michigan shoreline.

Open fields, most of which are abandoned agricultural land, make up 5.1 percent of the island. Common juniper (Juniperus communis) and Rosa spp. are the only native woody plants within deer reach found in the open fields. Domestic apple and cherry orchards occur in some fields, and many of the apple trees produced fruit during the period of study.

Sand dunes and beaches constitute 3.2 percent of the island. Vegetation is sparse or absent from most of the sand dunes. Occasional woody plants in these areas include eastern white cedar, horizontal juniper (Juniperus horizontalis), and furry willow (Salix adenophylla). Scharf and Jorae (1980) stated that dune vegetation on NMI was characterized by bearberry (Arctostaphylos uva-ursi) and horizontal juniper; however, no bearberry was observed on NMI during this study.

Two inland lakes and their associated wetlands cover 2.0 percent of the island. Tamarack Lake is small and partially covered by quaking bog (Hatt et al. 1948), whereas Lake Manitou is a deep, clear lake with large marsh areas and cedar swamps at the north and south ends.

The vertebrate fauna of NMI is simple: 6 amphibian, 6 reptile, 16 mammal, and 189 bird species have been documented (Case and Scharf 1985; Scharf and Jorae 1980). Besides the white-tailed deer, large vertebrates present on the island include wild turkey (Meleagris gallapavo), red fox (Vulpes vulpes), raccoon (Procyon lotor), fox squirrel (Sciurus niger), and beaver (Castor canadensis). Snowshoe hares (Lepus americanus), once abundant on the island, are thought to be extirpated.

\section{History of the White-Tailed Deer Herd}

Deer are not indigenous to NMI. Five white-tailed does and four bucks obtained from Chambersburg, Pennsylvania were introduced to the island in 1926 (Michigan Department of Natural Resources application for game breeders license, submitted by the NMI Association in 1976). In the first organized hunt, conducted in 1937, 18 deer were harvested (Arnold and Bartlett 1968). Hunter kills and estimated winter mortality between 1937 and 1977 are summarized in table 2. Winter mortality during this period was estimated subjectively from the number of dead deer found in the vicinity of feeding stations. Most estimates were made by Ilo $\mathrm{H}$. Bartlett, former deer biologist for the Michigan Department of Natural Resources. As far as is known, no systematic, scientifically based estimates of herd size or winter mortality were made prior to our study (R. Huff, pers. comm.). No age structure of winter-killed or harvested deer was available prior to our study (Arnold 1970).

Deer were hunted on NMI by invited guests and North Manitou Island Association personnel. Initially, deer hunters travelled on foot or in vehicles with association guides (R. H. Rusco, pers. comm.). Beginning in the early 1960s blinds were constructed near 
TABLE 2. HUNTER KILL AND ESTIMATED WINTER MORTALITY OF WHITE-TAILED DEER ON NORTH MANITOU ISLAND

\begin{tabular}{|c|c|c|c|c|c|}
\hline Year & $\begin{array}{c}\text { Winter } \\
\text { mortality* }\end{array}$ & $\begin{array}{c}\text { Hunter } \\
\text { kill }\end{array}$ & Year & $\begin{array}{c}\text { Winter } \\
\text { mortality* }\end{array}$ & $\begin{array}{c}\text { Hunter } \\
\text { kill }\end{array}$ \\
\hline 1937 & $10^{\dagger}$ & 18 & 1958 & 40 & 233 \\
\hline 1938 & 0 & 41 & 1959 & 100 & 243 \\
\hline 1939 & 10 & 45 & 1960 & 75 & 224 \\
\hline 1940 & 0 & 95 & 1961 & 20 & 207 \\
\hline 1941 & 20 & 139 & 1962 & 500 & 202 \\
\hline 1942 & 50 & 176 & 1963 & 100 & 267 \\
\hline 1943 & 50 & 292 & 1964 & 150 & 250 \\
\hline 1944 & 50 & 302 & 1965 & 50 & 289 \\
\hline 1945 & 10 & 50 & 1966 & 50 & 282 \\
\hline 1946 & 50 & 138 & 1967 & 50 & 312 \\
\hline 1947 & 300 & 202 & 1968 & 50 & $\mathrm{nd}^{\ddagger}$ \\
\hline 1948 & 100 & 120 & 1969 & nd & nd \\
\hline 1949 & 50 & 174 & 1970 & nd & nd \\
\hline 1950 & 200 & 196 & 1971 & nd & 139 \\
\hline 1951 & 70 & 228 & 1972 & nd & nd \\
\hline 1952 & 75 & 274 & 1973 & nd & 69 \\
\hline 1953 & 30 & 238 & 1974 & nd & 124 \\
\hline 1954 & 100 & 289 & 1975 & nd & 161 \\
\hline 1955 & 50 & 286 & 1976 & nd & 203 \\
\hline 1956 & 70 & 245 & 1977 & nd & 507 \\
\hline 1957 & 20 & 266 & & & \\
\hline
\end{tabular}

SOURCE: Arnold and Bartlett (1968) and Michigan Department of Natural Resources reports. *Subjective estimate: no systematic surveys conducted.

${ }^{\dagger}$ Winter mortality for winter preceding the fall harvest.

${ }^{\ddagger}$ No data available.

feeding stations. Hunters were dropped off at the blinds with strict instructions not to leave the vicinity of the blinds. The hunter and deer were picked up later in the day (G. Grosvenor, pers. comm.). Each hunter was guaranteed a deer-if a hunter were unsuccessful, a deer would be shot for the hunter by association personnel. The last hunt conducted by the NMI Association took place in 1977-78, and harvested 507 deer.

An extensive deer feeding program was initiated by the owners of the island some time shortly after the first deer hunt in 1937 (Arnold 1970). In the 1940s and 1950s a pelleted ration was distributed in small wooden boxes placed on trees throughout the island (R. H. Rusco, pers. comm.). By 1968, the small boxes had been replaced with 34 large feeding troughs. In the winter of $1967-68,45 \mathrm{~kg}$ (100 pounds) of feed were distributed twice weekly to each trough. A total of $54,300 \mathrm{~kg}$ (60 tons) per year of pelleted food was distributed through 1976-77 (M. Grosvenor, pers. comm.). Only $3,600 \mathrm{~kg}$ ( 4 tons) of feed were distributed in 1977-78, and there has been no feeding since that time. The composition of the deer feed in the early years is unknown. In the 1970s, however, the food was pelleted alfalfa and salt (M. Grosvenor, pers. comm.). At the onset of this study in June 1980, there had been neither supplemental feeding nor hunting for 3 years. 


\section{METHODS}

\section{Line-Transect Population Estimate}

Systematic deer counts were made throughout both field seasons from a motorcycle travelling at speeds between 13 and $20 \mathrm{~km}$ per hour. The motorcyclist concentrated on a 30- to 40-m semicircular area ahead of the vehicle, but attempted to observe as many deer as possible. For all deer observed, the distance from the animal to the center of the road when first observed was recorded. In addition, the age, sex, habitat type, group size, and group composition were recorded when possible.

Counts were made just before sunset or just after sunrise, and required 1.5 to 2.5 hours to complete. Counts were not conducted under extreme weather conditions such as heavy fog, rain, or high winds. Three routes were established along passable roads and trails so that all parts of the island were sampled (fig. 2). Sixty-eight counts were made between July and October of 1980 and 48 counts between May and August of 1981. In 1980, counts were made periodically whenever time and weather conditions allowed. In 1981, twelve counts, four on each route and six each in the morning and evening, were conducted each month. The three routes were also shortened between 1980 and 1981 to eliminate overlap.

Burnham and Anderson (1976) listed seven assumptions necessary to line-transect population estimates:

1. Objects are distributed independently in an infinite plane according to some stochastic process.

2. A series of randomly located lines of known length transverse the plane, and the number of objects on both sides of the line are observed and the right-angle distances are recorded.

3. There is a function that is the conditional probability of observing an object, given its right-angle distance from the line.

4. Objects exactly on the line are never missed.

5. Objects are fixed, no confusion arises over objects that move during sampling, and no object is counted twice.

6. There are no measurement errors.

7. Sightings are independent events.

Considerable work has gone into developing parametric methods for estimating density from line-transect data (Gates, Marshall, and Olson 1968; Sen, Tovrigny, and Smith 1974; Burnham and Anderson 1976; Caughley 1977). Burnham and Anderson cautioned against the use of parametric estimators because it is difficult to satisfy their assumptions. They recommended nonparametric estimators that do not assume a parametric distribution (e.g., exponential, gamma, logistic). Eberhardt (1968) suggested that nonparametric estimates be calculated and reported along with parametric estimates.

For line-transect analyses, three counts (one from each route) were combined as a survey. Population estimates were computed for each survey. Because all routes were not sampled equally in 1980, 12 counts ( 4 from each route) were randomly selected from each month and combined into four surveys. In 1981, data were used from all counts.

The visibility and behavior of deer were much different during May, since spring leaf emergence had not yet taken place. Because it was desirable to compare estimates made 


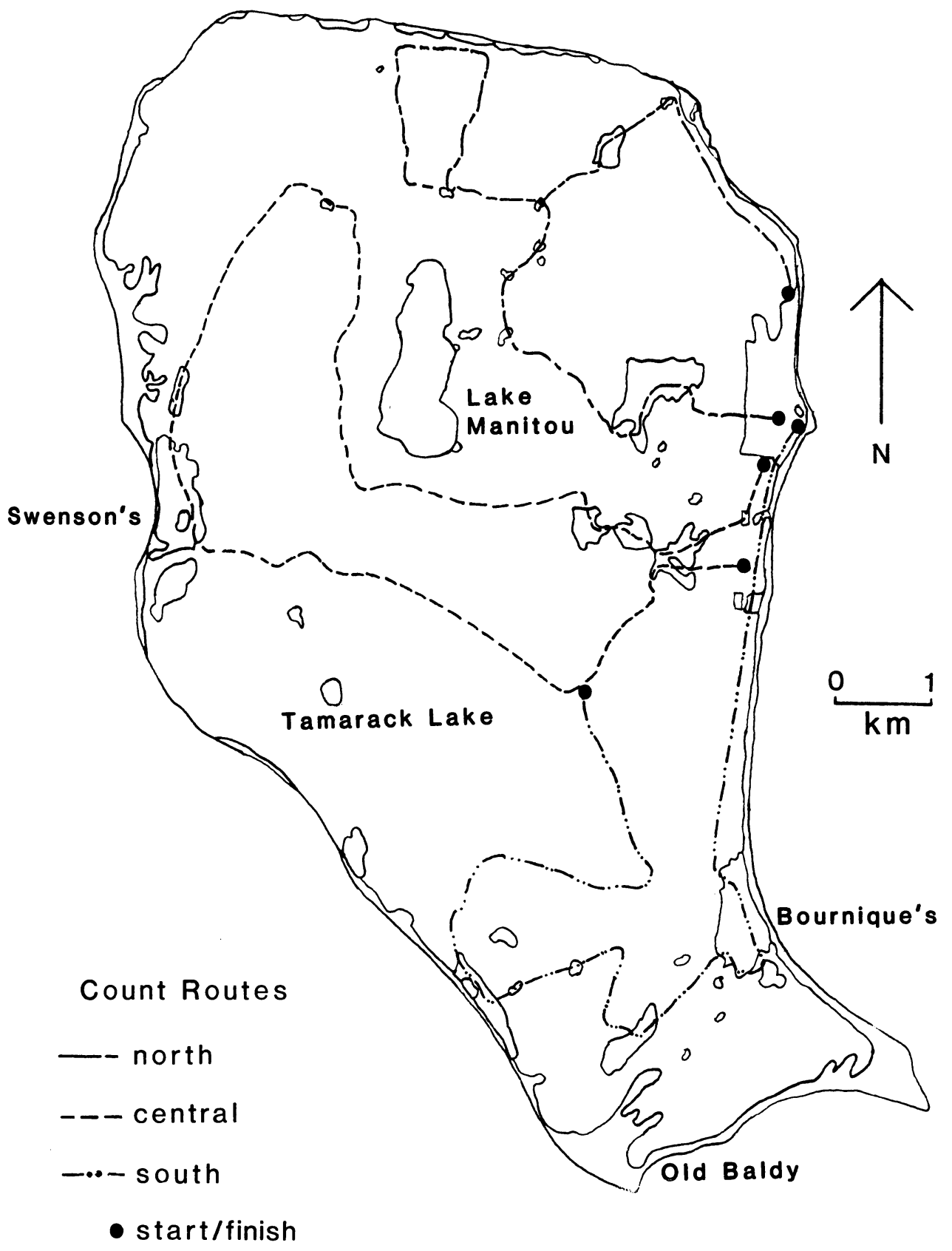

Fig. 2. Systematic deer count routes used on North Manitou Island, Michigan, in 1980 and 1981. 
under similar conditions, data from counts conducted in May 1981 were not used to compute population estimates by the line-transect method.

Although transect (road) locations were broadly distributed over habitat types, types were disproportionately sampled relative to their abundance. Therefore, population estimates were computed for three habitat strata (northern hardwood forest, selectively cut northern hardwood, and open field) and then combined to form a total estimate. Separate estimates were computed for adults (including yearlings) and fawns. Linetransect data were analyzed by two nonparametric methods (Anderson and Pospahala 1970; Gates, Marshall, and Olson 1968) and one parametric method (Kelker 1945) based on right-angle distances.

By fitting a mathematical equation to the perpendicular distances at which deer were observed, the Anderson and Pospahala (1970) method of line-transect data analysis corrects for the inability of observers to locate all objects at increasing distances from the center of the transect. Perpendicular distances were grouped into 5-m class intervals and a histogram was constructed for each month and habitat type. Figure 3 illustrates typical histograms for the three habitat types. An attempt was made to group distances by survey, but the sample sizes were too small to give significant equations. This method was not used to determine fawn population size because of the relatively small number of fawns observed each month.

Second-degree polynomials were fitted to the data from each histogram by leastsquares regression. The dependent variable was the number of deer observed in a particular interval and the independent variable was the distance interval from the center line of the transect to the midpoint of the class interval. Based on the $F$ distribution, all of the 21 transect lines were significant at the 0.90 level and all but five were significant at the 0.99 level (table 3 ). $R$ values ranged from 0.64 to 0.95 .

The area under the curve in figure 4 represents the number of deer observed on the transect. The total number of deer present on the transect is represented by the area below a horizontal line extending from the $y$-intercept to the maximum perpendicular

TABLE 3. REGRESSION STATISTICS $(r, F)$ AND CORRECTION FACTORS (FACTOR) FOR LINE-TRANSECT ESTIMATES BY THE ANDERSON AND POSPAHALA (1970) METHOD DERIVED BY HABITAT TYPE AND YEAR ON NORTH MANITOU ISLAND

\begin{tabular}{|c|c|c|c|c|c|c|c|c|c|}
\hline \multirow{3}{*}{$\begin{array}{l}\text { Year and } \\
\text { month }\end{array}$} & \multicolumn{9}{|c|}{ Habitat type } \\
\hline & \multicolumn{3}{|c|}{ Northern hardwoods } & \multicolumn{3}{|c|}{ Selective cut } & \multicolumn{3}{|c|}{ Open field } \\
\hline & $r$ & $F$ & Factor & $r$ & $F$ & Factor & $r$ & $F$ & Factor \\
\hline \multicolumn{10}{|l|}{1980} \\
\hline July & .77 & 8.86 & 3.57 & .92 & 35.32 & 3.78 & .88 & 27.80 & 2.50 \\
\hline August & .78 & 9.62 & 2.44 & .89 & 23.80 & 2.93 & .91 & 40.09 & 2.84 \\
\hline September & .82 & 12.77 & 1.97 & .95 & 51.25 & 3.22 & .88 & 28.20 & 2.13 \\
\hline October & .77 & 9.02 & 1.75 & .78 & 9.68 & 1.47 & .66 & 6.41 & 1.28 \\
\hline \multicolumn{10}{|l|}{1981} \\
\hline May & .78 & 13.23 & 2.38 & .66 & 4.69 & 0.78 & .71 & 4.55 & 2.17 \\
\hline June & .87 & 19.52 & 2.56 & .86 & 16.37 & 2.57 & .85 & 22.74 & 2.44 \\
\hline July & .69 & 5.35 & 2.19 & .67 & 4.92 & 2.29 & .80 & 15.09 & 2.79 \\
\hline August & .64 & 4.10 & 1.79 & .93 & 30.54 & 3.06 & .67 & 4.90 & 1.74 \\
\hline
\end{tabular}



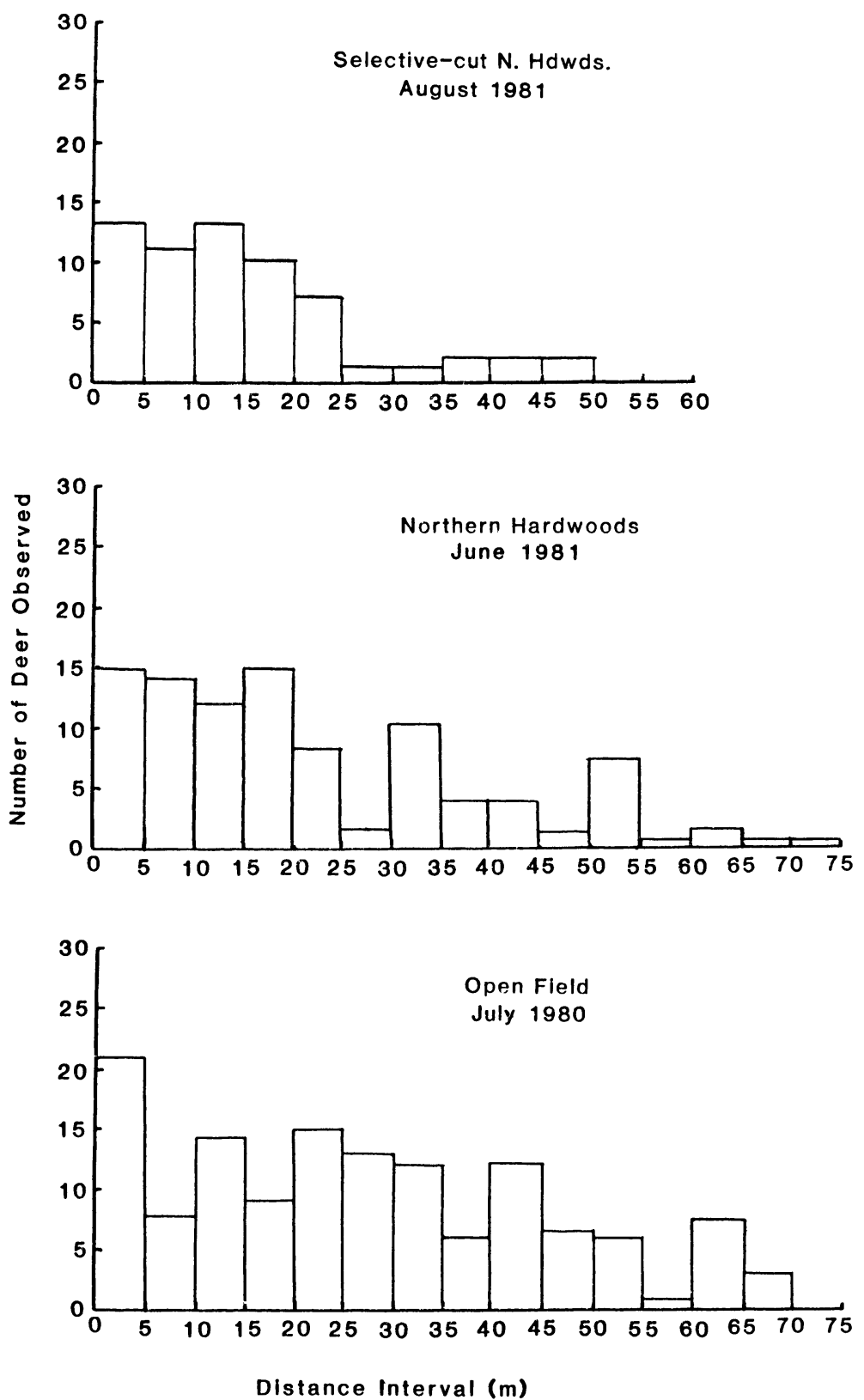

Fig. 3. Typical histograms for three habitat types used for computing deer population estimates by the line-transect method on North Manitou Island. 


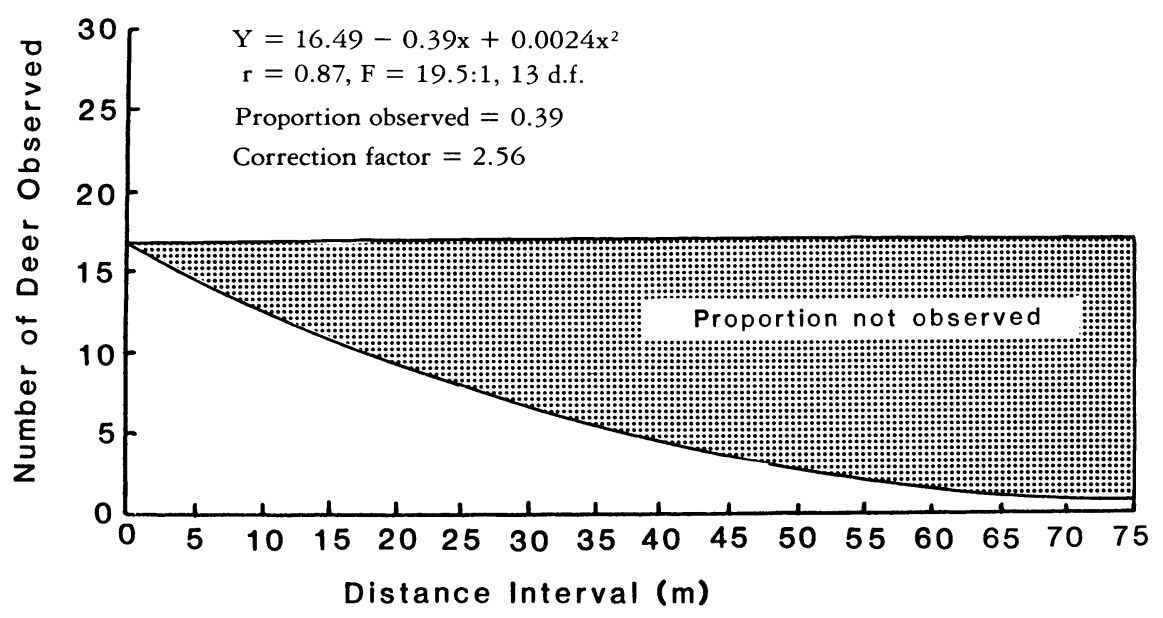

Fig. 4. Second-degree polynomial equation used to represent the relationships between distance from the center line of the transect and the number of deer observed in the northern hardwood forest type in June 1981 on North Manitou Island.

distance. The proportion of deer observed was determined by dividing the area under the curve by the area under the horizontal line. The inverse of this relationship was used as a correction factor. Correction factors were determined for each habitat and for each month (table 3 ). We estimated population size $(N)$ with the formula

$$
N=n^{\prime} A / 2 L D \text {, }
$$

where $n^{\prime}$ is the corrected number of deer on transect, $D$ is the maximum perpendicular distance used, $A$ is the area censused, and $L$ is the length of census lines.

TABLE 4. PERPENDICULAR DISTANCES FROM CENTER LINE

WITHIN WHICH ALL DEER WERE ASSUMED TO HAVE BEEN OBSERVED

TO CALCULATE POPULATION ACCORDING TO KELKER (1945)

\begin{tabular}{lccc}
\hline \hline & \multicolumn{3}{c}{ Habitat type } \\
\cline { 2 - 4 } Year and month & Northern hardwood & Selective cut & Open field \\
\hline & $-----1---1$ & \\
1980 & & & \\
July & 25 & 15 & 35 \\
August & 30 & 20 & 40 \\
September & 30 & 20 & 40 \\
October & 20 & 20 & 45 \\
1981 & & & \\
May & 25 & 30 & 40 \\
June & 20 & 15 & 45 \\
July & 15 & 15 & 45 \\
August & 30 & 20 & 25 \\
\hline
\end{tabular}


Gates, Marshall, and Olson (1968) used a negative exponential curve to describe the distribution of right-angle distances. They estimated population size with the formula

$$
N=(n-1) A / 2 L Y,
$$

where $n$ is the number of animals observed on the transect and $Y$ is the mean perpendicular distance. Using this method, we counted all the deer observed on the transect when computing the estimates, regardless of the deer's distance from the center of the transect. We computed estimates for adults and fawns for each survey and habitat type.

Kelker's (1945) nonparametric method involved determining the perpendicular distance within which it was believed that all deer were observed. We determined this distance by examining the previously described histograms (fig. 3). The distance varied with habitat type and season (table 4). We computed population estimates for both adults and fawns with the formula

$$
N=n^{\prime \prime} A / 2 L D^{\prime},
$$

where $n^{\prime \prime}$ is the number of deer seen within $2 D^{\prime}$ and $D^{\prime}$ is the estimated perpendicular distance beyond which some deer were probably missed. For further discussion of the line-transect survey procedures, calculations, and evaluations of assumptions, see Case (1982).

\section{Pellet-Group Population Estimate}

A pellet-group survey was conducted in May 1981 to estimate population size. Pellet groups were counted on 200 circular plots of $10 \mathrm{~m}^{2}$ each, spaced at $50-\mathrm{m}$ intervals along 26 transects (fig. 5). The island was stratified into four habitat types and plots were apportioned to type according to the proportion of each plot represented by that habitat type and according to expected deer use of that type.

The plot boundaries were delineated by extending a cord from a stake at the plot center. Two researchers searched each plot carefully. Aggregations of fewer than 20 pellets were not considered groups (Neff 1968). Pellet groups on the plot boundary were tallied if more than half of the pellets were within the plot.

All groups present on top of leaf litter from the previous fall were considered "new" and were tallied. Groups occurring on plots in areas devoid of sufficient deciduous leaf litter were not counted if $(1)$ insect holes, fungus, mold, or moss were present in or on the pellets; (2) any apparent structural decay of the pellets had occurred; (3) pellets were embedded in vegetation from the previous year; or (4) no concensus could be reached between observers. All pellet counts were made under relatively dry conditions.

No information was available on pellet group deposition rates on NMI, so the rate of 13.4 groups per deer per day, which had been developed for deer in northern lower Michigan (Burgoyne and Moss 1981), was used to derive a population estimate. 


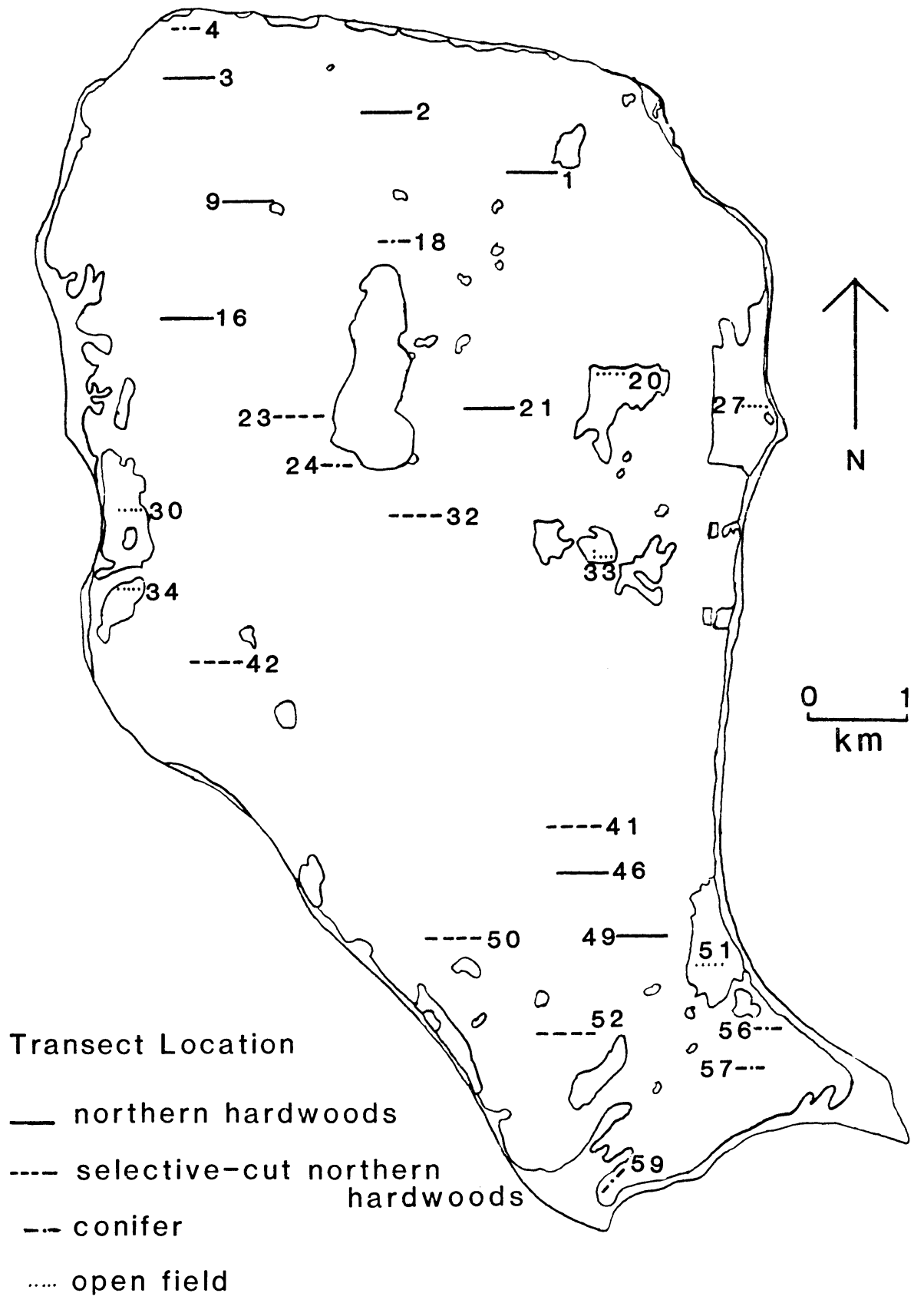

Fig. 5. Location of transects by habitat type used for pellet-group survey, twig count, vegetation survey, and vegetation monitoring system in 1981 . 


\section{Dead Deer Surveys}

In the summer of 1980 , dead deer surveys were undertaken to determine winter mortality during the previous three winters. Winter mortality was known to be very high in 1977-78 (J. Vogt, pers. comm.) and the locations of a number of carcasses from that winter were known ( $M$. Holden, pers. comm.). After examining these carcasses, we developed the following criteria to determine year of death: (1) presence of decay or crumbling bones, indicating the deer died prior to 1977-78; (2) burial of the carcass under substantial humus or litter, indicating the deer died before 1977-78; (3) subjective evaluation based on the presence or absence of tendons, blood stains, and vegetation stains; and (4) comparison with nearby carcasses of known year of death.

For each carcass, the sex, estimated age (Severinghaus 1949), estimated year of death, location, and habitat type were recorded. The femur marrow cavity of newer carcasses was examined to determine probable cause of death (Cheatum 1949)-whether by winter starvation or by hunter injury. Deer carcasses with severely depleted marrow fat were considered to have died of starvation.

Easily accessible areas with high expected concentrations of carcasses were searched completely. Two researchers walked parallel lines back and forth across an area until the entire area was searched. Spacing between researchers varied from 8 to $15 \mathrm{~m}$ depending on habitat type and terrain. Areas that were searched by this method were usually either small or linear, such as the shorelines of Lake Manitou and Lake Michigan (fig. 6). In total, 1,138.9 ha were searched completely in 1980.

Large areas with high to moderate expected concentrations of carcasses were searched by the line-transect method. The first transect on each area was randomly located and spacing between the parallel transects varied from 40 to $75 \mathrm{~m}$ depending on the size of the sampled area and the time available. Transects were perpendicular to the terrain features of each site censused. The line of travel for each transect was maintained with a hand-held compass as the researcher proceeded across the area. Transect lengths were measured by pacing. The perpendicular distance of each carcass from the transect line was recorded to the nearest 0.25 pace and later converted to meters. One hundred seventy-four ha were censused by the line-transect method in 1980 (fig. 6). A total of $17.93 \mathrm{~km}$ of transects was covered.

The greatest proportion of the total estimated mortality during the winters of 1977-78, 1978-79, and 1979-80 was estimated by line-transect sampling. To be consistent with estimates of population size, results obtained by the Kelker (1945) method were selected to estimate total winter mortality. All the assumptions of line-transect sampling were probably met. Analysis of line-transect data followed Kelker's method. For the Kelker method, we concluded that all carcasses within $3.0 \mathrm{~m}$ of the transect center were located. Data were combined for all areas and for deer having died during the winters of 1977-78, 1978-79, and 1979-80.

The winter of 1976-77 was the last time the full feeding program was carried out. Only 3,600 kg ( 4 tons) were fed to the deer during the next winter (M. Grosvenor, pers. comm.). To determine how many deer died near feeding stations in the winter of $1977-78,14$ of the 35 stations were randomly selected and the area within a $100 \mathrm{~m}$ radius of the center of each of these stations was searched.

Two areas where the concentrations of carcasses were expected to be relatively high were searched by dividing each area into plots of equal size and then searching a 


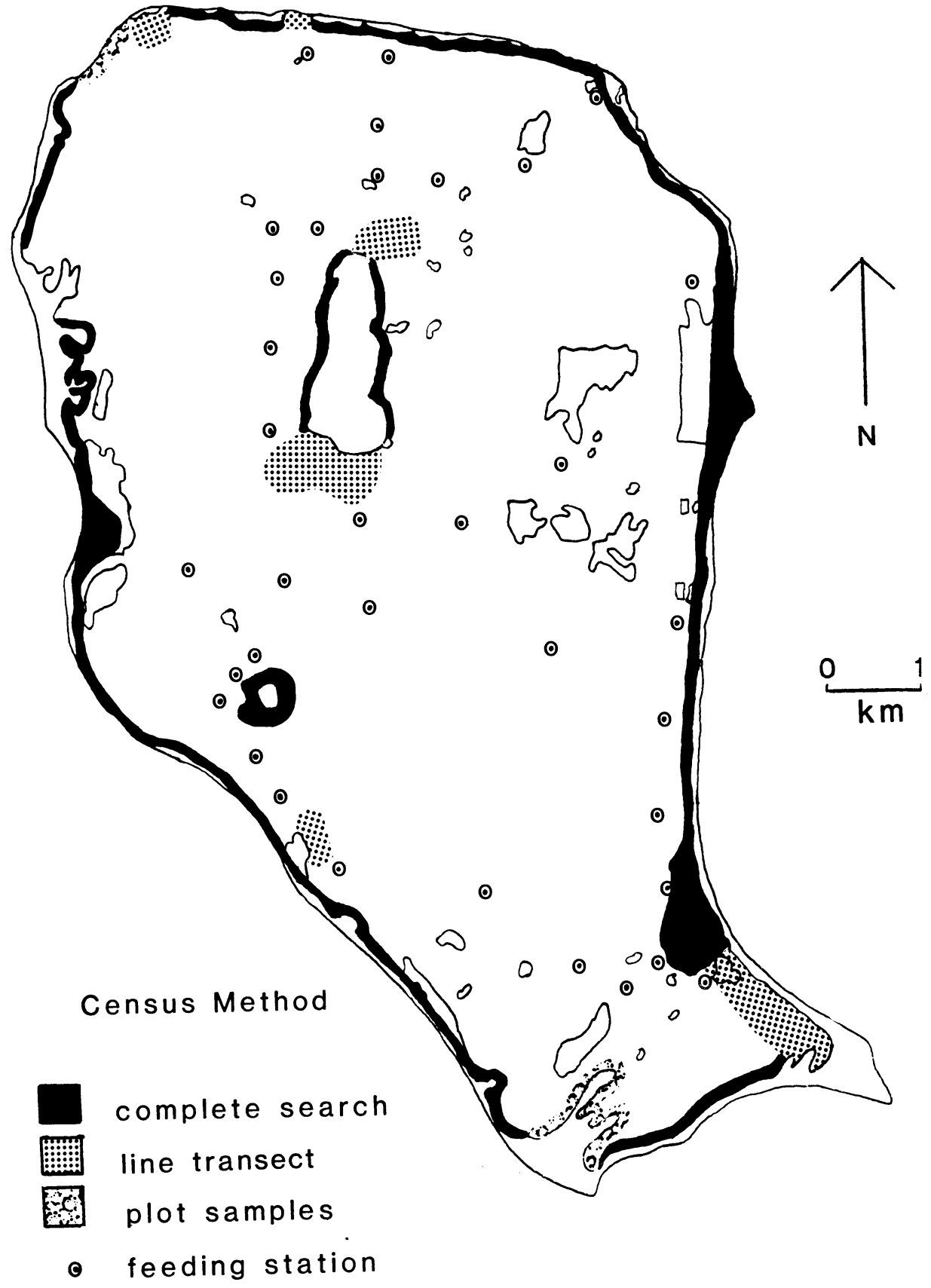

Fig. 6. Locations of dead deer censuses in 1980. 
random sample of those plots. Both of these areas were on very steep slopes not conducive to the line-transect method. The first area was in the vicinity of Old Baldy in the southwest portion of the island (fig. 6). This area consisted of a 16.2-ha band of conifers (northern white cedar and eastern hemlock) bordering a number of large sand dune blowouts. The band of conifers was divided into 27 plots, and 10 were selected at random and searched for carcasses.

The second area was on the shoreline of Lake Michigan on the northwest portion of the island. This area consisted of 12.8 ha of steep slope covered by northern white cedar. The area was divided into eight plots of equal size and three of the plots were randomly selected and searched for carcasses.

Two methods were used to estimate 1980-81 winter mortality. The number of carcasses present on 129 ha was determined by complete search in June 1981. The number of carcasses on the remaining portion of the island was estimated by searching 25 random $40-\times 1,000$-m plots (fig. 7). All plots were oriented in an east-west direction perpendicular to terrain features such as ridges and valleys. The number of carcasses of deer believed to have died in the winters of 1977-78, 1978-79, and 1979-80 were also recorded on these plots. Estimates were computed separately for the winters of 1977 through 1980 and of 1980-81.

Dead deer surveys conducted in May 1982 were similar to those conducted in 1981, but had to be modified because of time constraints. One hundred six ha were searched completely in 1982 by the methods used in previous years. The number of carcasses on the remaining portion of the island was estimated by searching $1550-\times 1,000-\mathrm{m}$ plots (fig. 8). Plots were not randomly located, but rather were the areas transversed in travelling from one area of complete search to another. Based on results from previous surveys, we did not believe this method of plot placement to be systematically biased. Plots were searched by three researchers spaced across the 50 -m width.

\section{Physical Condition of Deer}

In October 1980, 32 live deer were collected for autopsy by the senior author, the Michigan Department of Natural Resources, and Park Service biologists. Whole body weight was measured with a suspended spring scale. Kidney fat index (KFI) was determined using the method of Riney (1955). The lower jaw of each deer was removed and age was estimated by tooth wear and replacement (Severinghaus 1949). Ether-extractable fat levels in the mandibular cavity tissues (MF) were estimated by calculating the wet and dry weights of marrow (Friedrich and Burgoyne 1980) at the Michigan Department of Natural Resources Wildlife Pathology Laboratory.

John Stuht of the Michigan Department of Natural Resources conducted a parasite examination on the 32 deer. Feces were analyzed for parasites by sugar flotation. The braincase, nasal cavity, and all internal organs were examined for the presence of parasites and disease.

\section{Vegetation Surveys}

We conducted a winter browse survey in May 1981, in conjunction with the pellet-group survey. The same plot centers described for the pellet-group population 


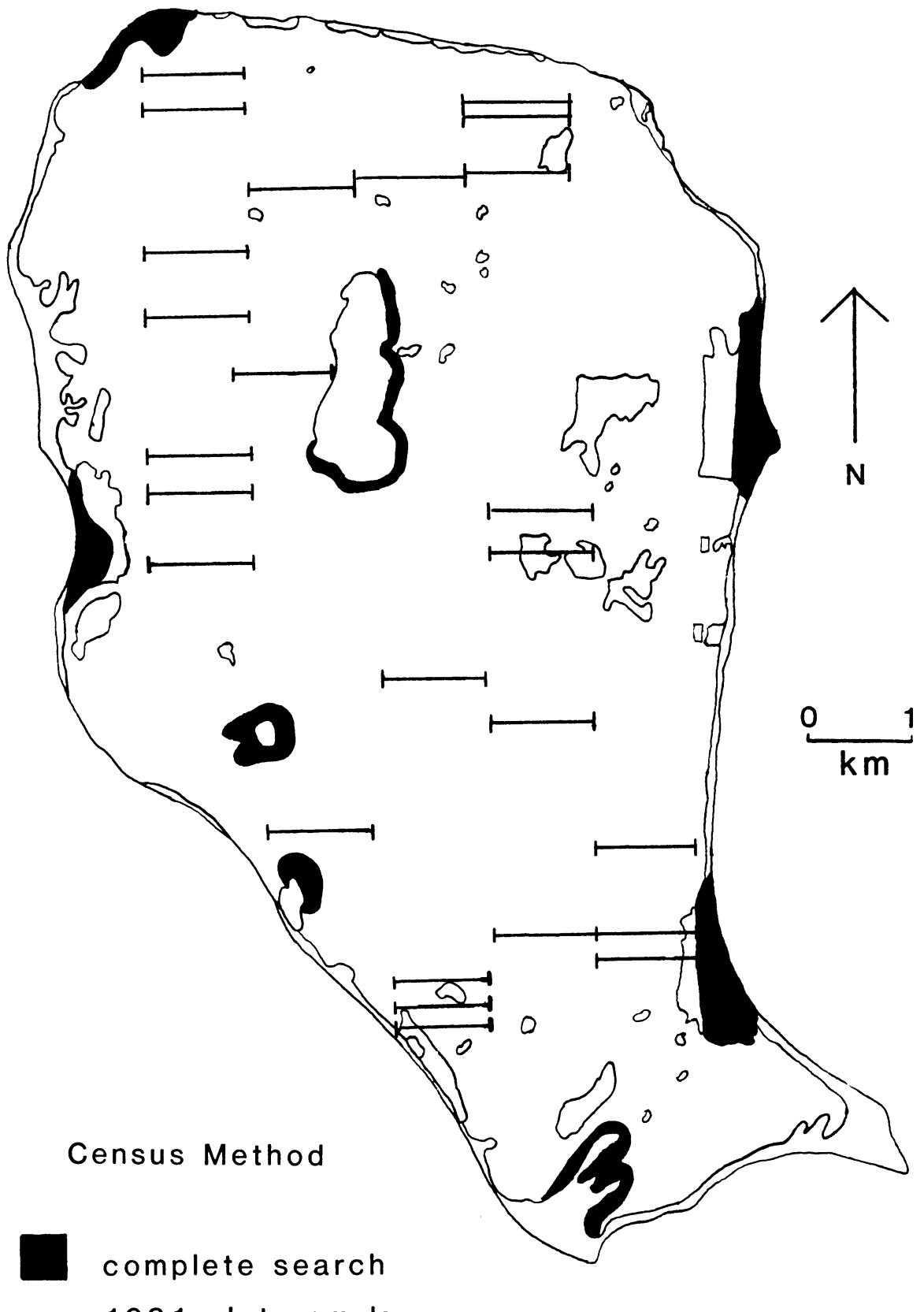

$\longmapsto 1981$ plot sample

Fig. 7. Locations of dead deer censuses in 1981. 


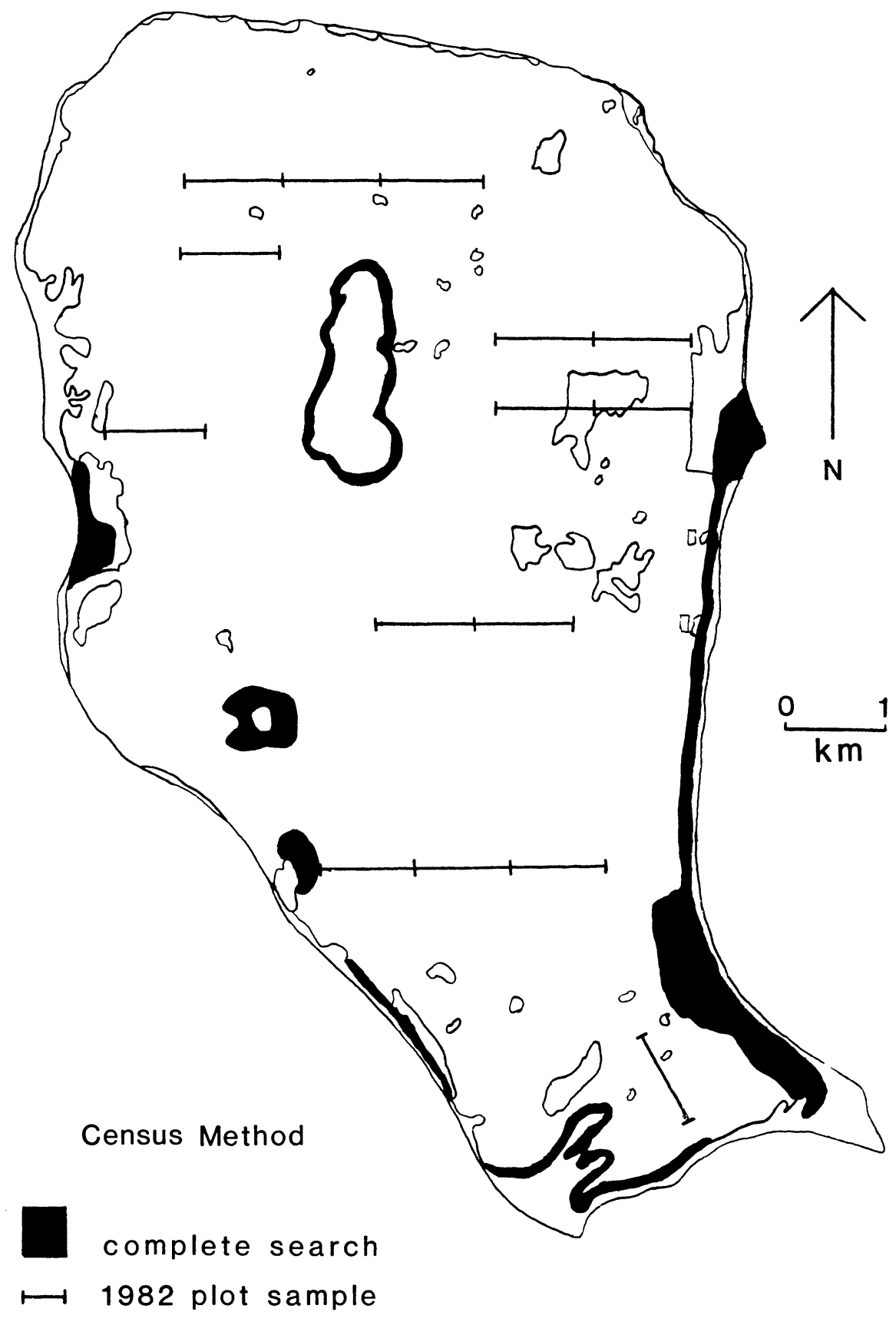

Fig. 8. Locations of dead deer censuses in 1982. 
estimate were used (fig. 5). The numbers of browsed and unbrowsed twigs were recorded by species on $2006-\mathrm{m}^{2}$ plots. A twig was defined as the growth of $2.5 \mathrm{~cm}$ or more from the most recent growing season. A twig was considered browsed if any portion of this growth had been removed by deer. Only twigs within deer reach (approximately $1.8 \mathrm{~m}$ from the ground) were recorded.

The basal diameter of all woody plants with foliage within $1.8 \mathrm{~m}$ of the ground was measured on 100 of the 6- $\mathrm{m}^{2}$ plots (every other one). Regression equations developed by the junior author on the E. S. George Reserve in southern Michigan were used to estimate the leaf and twig biomass of each plant. Utilization was determined in the same manner as for herbaceous plants.

The production and utilization of herbaceous plants and deciduous leaves and twigs were inventoried in July and August 1981 on the 200 plots previously described. Herbaceous vegetation production was estimated by clipping all vegetation on 100 $1-\mathrm{m}^{2}$ circular plots (every other one), separated by species (grasses and sedges were combined), oven-dried at $60^{\circ} \mathrm{C}$ for 72 hours, and weighed to the nearest gram. Before clipping, each plot was examined for herbaceous stems that had been fed upon by deer. When clipped stems were found, a plant of similar size was collected outside of the plot and saved for drying and weighing. The dry weights of all such plants provided an estimate of deer utilization (Belovsky 1978). Grasses and sedges were clipped and weighed, but no estimate of removal was obtained.

\section{Rumen Analysis}

One-quart samples of rumen contents were collected from each of 31 of the 32 deer harvested in October 1980, and then preserved in 10 percent formalin solution. In the laboratory, each rumen sample was thoroughly washed with water through a $5-\mathrm{mm}$ sieve and analyzed using a variation of the point-frame technique described by Chamrad and Box (1964). A number of investigators (Chamrad and Box 1964; Robel and Watt 1970; Puglisi, Liscinsky, and Harlow 1978) have found that large items such as acorns or apples bias the results. To circumvent this bias, we first separated apples, acorns, and fungi and measured them volumetrically. The remaining contents were measured volumetrically and then subjected to point-frame analysis. Contents were spread evenly in a $17-\times 28-\mathrm{cm}$ laboratory tray and 100 points were determined by the method of Chamrad and Box (1964). Each plant fragment was classified to genus and species when possible. Unidentified specimens were labeled and identified at the University of Michigan Herbarium by Dr. A. A. Reznicek.

All hits were classified after McCaffery, Tranetzki, and Piechura (1974) into 3 forage categories; herbaceous (herbs, leaves, and petioles), flowers and fruits (including fungi), and woody browse (twigs and stems of trees and shrubs). Grasses and sedges were collectively called graminids, and fungi were grouped together under Agaricaceae (McCaffery, Tranetzki, and Piechura 1974).

The percent volume, percent occurrence, and importance value were computed for each food item. Percent occurrence was calculated by dividing the number of rumina in which a food item occurred by the total number of rumina. The importance value is a rating factor determined by multiplying the percent occurrence by the percent volume (McCaffery, Tranetzki, and Piechura 1974). 


\section{Vegetation Measurement in a Deer Exclosure}

Production of herbaceous plants and deciduous leaves and twigs were inventoried inside a 5- $\times 5$-m deer exclosure erected in 1962 (Scharf and Jorae 1980) in a northern hardwoods forest north of Lake Manitou. In August 1981, all herbaceous vegetation on two randomly located $1-\mathrm{m}^{2}$ circular plots inside the exclosure was clipped, separated by species, oven-dried at $60^{\circ} \mathrm{C}$ for 72 hours, and weighed to the nearest gram. The basal diameter of all woody plants with foliage within $1.8 \mathrm{~m}$ of the ground was measured on both plots. Regression equations developed on the E. S. George Reserve in southern Michigan were used to estimate leaf and twig biomass.

\section{Rate of Old-Field Succession}

The impact of deer browsing on old-field succession was assessed by evaluating low-altitude aerial photographs taken in August 1952. These allowed identification of individual trees and shrubs. The photos were compared to on-the-ground examinations of the same fields in 1981. The same procedure was followed in assessing old-field succession on South Manitou Island. Both islands have similar soils, vegetation types, and agricultural histories of the old fields. However, no deer have ever been present on SMI.

\section{RESULTS}

\section{Population Dynamics}

\section{Line-Transect Population Estimate}

Estimates of adult population size by the Anderson and Pospahala (1970) method in 1980 varied between 321 and 995, with a mean of $609 \pm 97$ ( \pm 0.95 confidence interval) (table 5). In 1981 the mean estimated adult population was $982 \pm 218$.

Estimated adult population size using the Kelker (1945) nonparametric method was $873 \pm 158$ in 1980 and $1,308 \pm 299$ in 1981 (table 6). Data gathered on fawns prior to August were not used because of the secretive habits of fawns during early life. Fawn population size was estimated at $574 \pm 215$ in 1980 and $513 \pm 270$ in 1981 (table 6). Fawn estimates in 1980 were 66.4 percent higher when data from August, September, and October were included than when August alone was included. This proportion was applied to August 1981 data, resulting in an adjusted estimate of $772 \pm 406$ fawns.

The Gates, Marshall, and Olson (1968) parametric method yielded an adult population estimate of $842 \pm 123$ in 1980 and 1,322 \pm 314 in 1981 (table 7). The estimated fawn population was $507 \pm 158$ in 1980 and $400 \pm 154$ in 1981 . The adjusted fawn estimate in 1981 was $590 \pm 227$.

The data in table 8 give the 1980 and 1981 prefawn and prehunt population sizes computed by the three line-transect methods. Adult and fawn population estimates that were computed by the Kelker (1945) method and the Gates, Marshall, and Olson (1968) 
TABLE 5. ESTIMATED ADULT DEER POPULATION IN 1980 AND 1981, USING THE REGRESSION CORRECTION FACTOR METHOD (ANDERSON AND POSPAHALA 1970)

\begin{tabular}{lccc}
\hline & & \multicolumn{2}{c}{ Year } \\
\cline { 3 - 4 } Month & Survey number & $1980 *$ & $1981 *$ \\
\hline \multirow{3}{*}{ June } & 1 & & 830 \\
& 2 & & 960 \\
& 3 & & 1,292 \\
July & 4 & 640 & 685 \\
& 1 & 535 & 942 \\
& 2 & 788 & 626 \\
August & 3 & 604 & 719 \\
& 4 & 426 & 995 \\
& 1 & 571 & 814 \\
September & 2 & 995 & 782 \\
& 3 & 476 & \\
& 4 & 828 & \\
October & 1 & 799 & \\
& 2 & 519 & \\
& 3 & 791 & \\
Mean \pm 0.95 & 4 & 489 & \\
confidence interval & 1 & 513 & \\
\hline
\end{tabular}

*Blank spaces indicate that no surveys were taken during that time.

method were not significantly different in 1980 or $1981(P>0.05)$. Adult estimates computed by the Anderson and Pospahala (1970) method were significantly lower than estimates computed by the Kelker (1945) or Gates, Marshall, and Olson (1968) method $(P<0.05)$. Adult population sizes computed by the latter two methods were similar to the estimate obtained from our spring pellet survey (table 8).

Population estimates by all methods (table 8 ) were gratifyingly similar. However, we concluded that the Kelker and the Gates, Marshall, and Olson methods provided the best estimates of the actual deer population size on NMI. The estimates obtained by these methods were not significantly different $(P>0.05)$, were similar to the pellet group estimate, and were the only methods that provided separate estimates of adult and fawn population size. To maintain consistency throughout the text the Kelker estimates (table 8), which were based on fewer critical assumptions, were arbitrarily chosen over the Gates, Marshall, and Olson estimates for assessment of herd dynamics and reproductive rates. 
TABLE 6. ESTIMATED ADULT AND FAWN POPULATIONS IN 1980 AND 1981, USING THE KELKER (1945) METHOD

\begin{tabular}{|c|c|c|c|c|c|}
\hline \multirow[b]{3}{*}{ Month } & \multirow[b]{3}{*}{ Survey number } & \multicolumn{4}{|c|}{ Year } \\
\hline & & \multicolumn{2}{|c|}{$1980 *$} & \multicolumn{2}{|c|}{$1981 *$} \\
\hline & & Adults & Fawns & Adults & Fawns \\
\hline June & $\begin{array}{l}1 \\
2 \\
3 \\
4\end{array}$ & & & $\begin{array}{l}1,246 \\
1,396 \\
1,315 \\
1,682\end{array}$ & \\
\hline July & $\begin{array}{l}1 \\
2 \\
3 \\
4\end{array}$ & $\begin{array}{l}760 \\
493 \\
875 \\
705\end{array}$ & & $\begin{array}{r}794 \\
1,535 \\
835 \\
729\end{array}$ & \\
\hline August & $\begin{array}{l}1 \\
2 \\
3 \\
4\end{array}$ & $\begin{array}{r}632 \\
917 \\
1,257 \\
518\end{array}$ & $\begin{array}{r}51 \\
568 \\
866 \\
38\end{array}$ & $\begin{array}{l}1,154 \\
1,455 \\
2,459 \\
1,102\end{array}$ & $\begin{array}{l}674 \\
572 \\
275 \\
532\end{array}$ \\
\hline September & $\begin{array}{l}1 \\
2 \\
3 \\
4\end{array}$ & $\begin{array}{r}1,367 \\
1,368 \\
738 \\
1,280\end{array}$ & $\begin{array}{r}821 \\
827 \\
870 \\
1,051\end{array}$ & & \\
\hline October & $\begin{array}{l}1 \\
2 \\
3 \\
4\end{array}$ & $\begin{array}{l}758 \\
970 \\
756 \\
581\end{array}$ & $\begin{array}{l}298 \\
734 \\
334 \\
436\end{array}$ & & \\
\hline $\begin{array}{l}\text { Mean } \pm 0.95 \\
\text { confidence interval }\end{array}$ & & $\begin{array}{c}873 \pm 158 \\
(n=16)\end{array}$ & $\begin{array}{c}574 \pm 215 \\
(\mathrm{n}=12)\end{array}$ & $\begin{array}{c}1,308 \pm 299 \\
(\mathrm{n}=12)\end{array}$ & $\begin{aligned} 513 & \pm 270 \\
(\mathrm{n} & =4)\end{aligned}$ \\
\hline
\end{tabular}

*Blank spaces indicate that no surveys were taken during that time.

\section{Pellet-Group Population Estimate}

The overall mean number of pellet groups deposited per plot per day between 29 October 1980 (leaf fall) and 17 May 1981 was $0.00326 \pm 0.00099$ ( \pm 0.95 confidence interval). This mean was adjusted to account for the different time periods for plots checked between the start and finish ( 5 May and 17 May) of the survey. The pelletgroup total was reduced to account for winter mortality. We estimated that 261 deer died during the winter of $1980-81$. Winter mortality was arbitrarily assigned to 20 February 1981. Researchers did not see dead or dying deer on 9 January 1981 but observed dying deer on 16 February 1981. Spring thaw occurred in late February, and March was unseasonably mild. Therefore, it was believed that most deer winter mortality occurred in late February. The total spring deer population on NMI estimated by the pellet-group survey was $1,230 \pm 420( \pm 0.95$ confidence level) (table 8).

The large number of plots containing no pellet groups made the confidence limit on the pellet-group survey quite wide. Variations attributable to different observers or to weather conditions were not important, since all plots were checked by the same two observers and under essentially the same weather conditions. 
TABLE 7. ESTIMATED ADULT AND FAWN POPULATIONS IN 1980 AND 1981, USING THE GATES, MARSHALL, AND OLSON (1968) METHOD

\begin{tabular}{|c|c|c|c|c|c|}
\hline \multirow[b]{3}{*}{ Month } & \multirow[b]{3}{*}{ Survey number } & \multicolumn{4}{|c|}{ Year } \\
\hline & & \multicolumn{2}{|c|}{$1980 *$} & \multicolumn{2}{|c|}{$1981 *$} \\
\hline & & Adults & Fawns & Adults & Fawns \\
\hline June & $\begin{array}{l}1 \\
2 \\
3 \\
4\end{array}$ & & & $\begin{array}{l}1,290 \\
1,313 \\
1,243 \\
1,562\end{array}$ & \\
\hline July & $\begin{array}{l}1 \\
2 \\
3 \\
4\end{array}$ & $\begin{array}{r}729 \\
543 \\
1,013 \\
762\end{array}$ & & $\begin{array}{r}864 \\
1,421 \\
811 \\
714\end{array}$ & \\
\hline August & $\begin{array}{l}1 \\
2 \\
3 \\
4\end{array}$ & $\begin{array}{r}535 \\
715 \\
1,115 \\
700\end{array}$ & $\begin{array}{r}308 \\
552 \\
460 \\
54\end{array}$ & $\begin{array}{l}1,634 \\
1,337 \\
2,595 \\
1,079\end{array}$ & $\begin{array}{l}403 \\
311 \\
352 \\
533\end{array}$ \\
\hline September & $\begin{array}{l}1 \\
2 \\
3 \\
4\end{array}$ & $\begin{array}{r}1,294 \\
1,216 \\
652 \\
1,023\end{array}$ & $\begin{array}{l}528 \\
826 \\
731 \\
913\end{array}$ & & \\
\hline October & $\begin{array}{l}1 \\
2 \\
3 \\
4\end{array}$ & $\begin{array}{l}802 \\
951 \\
747 \\
679\end{array}$ & $\begin{array}{l}220 \\
610 \\
525 \\
356\end{array}$ & & \\
\hline $\begin{array}{l}\text { Mean } \pm 0.95 \\
\text { confidence interval }\end{array}$ & & $\begin{array}{c}842 \pm 123 \\
(\mathrm{n}=16)\end{array}$ & $\begin{array}{c}507 \pm 158 \\
(\mathrm{n}=12)\end{array}$ & $\begin{array}{c}1,322 \pm 314 \\
(\mathrm{n}=12)\end{array}$ & $\begin{aligned} 400 & \pm 154 \\
(n & =4)\end{aligned}$ \\
\hline
\end{tabular}

*Blank spaces indicate that no surveys were taken during that time.

TABLE 8. WHITE-TAILED DEER POPULATIONS FOR 1980 AND 1981, ESTIMATED BY SEVERAL METHODS

\begin{tabular}{|c|c|c|c|c|}
\hline \multirow[b]{3}{*}{ Method } & \multicolumn{4}{|c|}{ Population size } \\
\hline & \multicolumn{2}{|c|}{ 1980* } & \multicolumn{2}{|c|}{$1981 *$} \\
\hline & Prefawn & Prehunt & Prefawn & Prehunt $^{\dagger}$ \\
\hline $\begin{array}{l}\text { Anderson and } \\
\text { Pospahala (1970) }\end{array}$ & $609 \pm 97$ & & $982 \pm 218$ & \\
\hline Kelker (1945) & $873 \pm 158$ & $1,447 \pm 373$ & $1,308 \pm 299$ & $2,080 \pm 705$ \\
\hline $\begin{array}{l}\text { Gates, Marshall, and } \\
\text { Olson (1968) }\end{array}$ & $842 \pm 123$ & $1,349 \pm 281$ & $1,322 \pm 314$ & $1,912 \pm 541$ \\
\hline Pellet Survey & & & $1,230 \pm 420$ & \\
\hline
\end{tabular}

*Blank spaces indicate that no census was conducted during that time.

${ }^{\dagger}$ Adjusted estimate-see text. 


\section{Sex and Age Structure}

The ratio of males to females for 654 fawns harvested between 1937 and 1977 was $1.15: 1$. Whether this ratio represents the overall fawn sex ratio in the population depends on whether male and female fawns are equally susceptible to hunting mortality.

Taber and Dasmann (1954), Robinette et al. (1957), and Coe, Downing, and McGinnes (1980) suggested that male fawns were more susceptible than female fawns to hunter mortality. Coe, Downing, and McGinnes and Taber and Dasmann thought that male fawns tended to travel without the doe more than females, and Coe, Downing, and McGinnes reported that male fawns with the doe were less susceptible to hunting mortality than were lone male fawns. Forty-five percent of 555 fawns observed between August and October 1980 were alone or with other fawns only. Hirth (1977) found that only 19 percent of the 286 fawns he observed on the George Reserve in southern Michigan between August and October were either alone or accompanied only by other fawns. Whether the high proportion of fawn-only groups observed in 1980 on NMI also occurred in years when hunts were conducted is not known.

In contrast to Hirth, McCullough (1979) found no sex differential among fawns collected by researchers on the George Reserve, where deer were collected by spotlight from a vehicle at night. Hunters in the blinds on NMI could easily distinguish fawns from adults in the field but could not distinguish male from female fawns. Therefore, it was believed that the harvest fawn sex ratios on NMI were similar to the population ratios.

The male-to-female ratio of adult deer (including yearlings) harvested from NMI between 1937 and 1980 was 1.41:1 (table 9). Significantly more males $(3,969)$ than females $(2,819)$ were removed during the period. The ratio of males to females harvested between 1937 and 1967 was 1.34:1. This increased to 1.85:1 for deer harvested between 1971 and 1977.

The sex ratio in the harvest depends upon decisions made in managing the herd, and does not accurately reflect the sex ratio in the population. Mean male to female ratios observed on four counts made each month in 1980 and 1981 varied somewhat from month to month as has been the case in other areas (table 10). Downing, Michael, and Poux (1977) reported that, in Virginia, counts in July had a higher proportion of males than expected, while counts conducted during August and November of most years had ratios similar to those expected. McCullough (1982a), working on the George Reserve in southern Michigan, found the male-to-female ratios observed on counts in July and August to be closest to the true ratio; in all other months males were significantly less observable than females.

We decided to base the adult sex ratios for our study on counts made in July and August, the only months during which data were collected in both years. This decision was deemed prudent in light of the studies cited above. The mean adult ratios of males to females (including yearlings) observed were $0.38 \pm 0.11: 1$ in 1980 and $0.39 \pm 0.11: 1$ in 1981 (table 10).

The age structure of 535 deer found dead on NMI between June 1980 and May 1982 indicated males were more susceptible to winter mortality. Few males survived more than 4.5 years. Relatively few females, however, died until they reached the older age classes. This resulted in an adult female age structure skewed toward the older age classes. The old age structure of females indicated by winter mortality was supported by the age distribution of six adult females and one hunter-killed deer collected in 1980, of 
TABLE 9. SEX RATIOS OF ADULT AND YEARLING DEER HARVESTED ON NORTH MANITOU ISLAND, FROM 1937 TO 1980

\begin{tabular}{lrrr}
\hline \hline Year(s) & Males & Females & Male-to-female ratio \\
\hline $1937-1967$ & 3,235 & 2,420 & $1.34: 1$ \\
$1971-1977$ & 724 & 391 & $1.85: 1$ \\
1980 & 10 & 8 & $1.25: 1$ \\
\cline { 2 - 4 } Total & 3,969 & 2,819 & $1.41: 1$ \\
\hline
\end{tabular}

TABLE 10. MALE-TO-FEMALE RATIOS OF ADULT AND YEARLING DEER OBSERVED ON LINE-TRANSECT SURVEYS IN 1980 AND 1981

\begin{tabular}{lcc}
\hline \hline & \multicolumn{2}{c}{ Male-to-female ratio } \\
\cline { 2 - 3 } Month & \multicolumn{1}{c}{$\mathbf{1 9 8 0 *}$} & $198 \mathbf{B}^{*}$ \\
\hline June & & $0.60 \pm 0.32: 1$ \\
July & $0.35 \pm 0.27: 1$ & $0.32 \pm 0.20: 1$ \\
August & $0.40 \pm 0.15: 1$ & $0.45 \pm 0.17: 1$ \\
September & $0.22 \pm 0.21: 1$ \\
October & $0.23 \pm 0.23: 1$ \\
\hline Mean \pm 0.95 & $0.38 \pm 0.11: 1$ & $0.39 \pm 0.11: 1$ \\
confidence interval (July-August) & & \\
\hline
\end{tabular}

*Blank spaces indicate that no census was conducted during that time.

which only one was under 4.5 years old. These results indicate a slight preponderance of males in the fawn age class, but a sex ratio skewed toward females among yearlings and adults, possibly because of selective harvest for males and greater winter mortality among males.

\section{Reproduction}

Under favorable food conditions, sexual maturity is common among white-tailed fawn females. However, little if any reproduction occurred in fawn females on NMI. Hesselton and Sauer (1973) hypothesized that the ability of fawn females to breed depended on whether they reached a threshold dressed weight of 29 to $32 \mathrm{~kg}$ ( 37 to 41 $\mathrm{kg}$ live weight) prior to the rut, and Harder (1980) supported this conclusion with a review of data from a number of northern deer herds. The whole body weight of 14 fawns collected in 1980 on NMI was $24 \mathrm{~kg}$, well under the $37 \mathrm{~kg}$ threshold. The $28 \mathrm{-kg}$ mean whole body weight ( $22-\mathrm{kg}$ dressed weight) of 83 fawns collected on NMI between 1971 and 1977 indicated that fawns probably did not breed during that period despite the intensive winter feeding program.

Information on the reproductive performance of does on NMI was obtained from observations made during line-transect counts. Fawn-to-doe ratios were computed by two methods: first, by dividing the total number of fawns observed by the total number of does (including yearlings) observed, and second, by dividing the number of fawns that accompanied does by the number of does with fawns. 
Computed by the first method, fawn-to-doe ratios increased each month after parturition (table 11). A gradual increase would have been expected as fawns began to spend more time travelling with their mothers (Hirth 1977; McCullough 1982a; Downing, Michael, and Poux 1977). However, in October of 1980 the fawn-to-doe ratio computed by the first method was unexpectedly high (1.73:1). Apparently does were less observable than fawns during late summer and early fall.

Fawn-to-doe ratios computed by the second method were much less variable (table 11). The mean fawn-to-doe ratio was $1.47 \pm 0.08$ in 1980 and $1.17 \pm 0.10$ in 1981 ( \pm 0.95 confidence interval). Ratios obtained in August (table 11) were used for comparisons between years. August fawn-to-doe ratios in other areas have consistently underestimated the known number of fawns per doe (Downing, Michael, and Poux 1977; McCullough 1982a). These estimates should be regarded as a minimum.

Separate estimates of fawn and adult population sizes provided another measure of reproductive success. The 1980 prefawn population size computed by the Kelker (1945) method was 873 deer (table 6). Assuming the July and August sex ratio estimates were accurate (table 10), 72.5 percent or 633 of these deer were female. The estimated fawn population was 574 in 1980. The fawn-to-doe ratio was then 0.91:1. This was below but close to the 1.04:1 ratio computed by method 1 from direct counts made in August 1980 (table 11). By computing in this same manner with adjusted fawn estimates gathered in 1981, we arrived at an estimated fawn-to-doe ratio of $0.82: 1$. This was higher than the 0.64:1 ratio observed on direct counts in August 1981 (table 11).

A comparison of fawn-to-doe ratios (table 11) indicated that productivity decreased from 1980 to 1981 . This decrease probably resulted from a decline in food supply as the herd increased and the female age structure changed. The change in female age structure can be illustrated by comparing the fawn-to-doe ratios computed by the two methods within each year. If all does had fawns, the two methods' ratios would be equal. However, as the number of does without fawns increased, the difference between the ratios should have increased. The ratios computed in 1981 had a much larger difference than those computed in 1980, indicating that a smaller proportion of the

TABLE 11. FAWN-TO-DOE RATIOS OF DEER OBSERVED BY DIRECT COUNT IN 1980 AND 1981

\begin{tabular}{|c|c|c|c|c|}
\hline \multirow[b]{2}{*}{ Month } & \multicolumn{2}{|c|}{1980} & \multicolumn{2}{|c|}{$1981 *$} \\
\hline & $\begin{array}{c}\text { Fawn-to-doe } \\
\text { ratio }\end{array}$ & $\begin{array}{c}\text { Fawn-to-doe } \\
\text { ratio }\end{array}$ & $\begin{array}{c}\text { Fawn-to-doe } \\
\text { ratio }\end{array}$ & $\begin{array}{c}\text { Fawn-to-doe } \\
\text { ratio }\end{array}$ \\
\hline July & $0.38 \pm 0.15: 1$ & $1.33 \pm 0.22: 1$ & $0.27 \pm 0.21: 1$ & $1.11 \pm 0.21: 1$ \\
\hline August & $1.04 \pm 0.45: 1$ & $1.59 \pm 0.26: 1$ & $0.64 \pm 0.30: 1$ & $1.22 \pm 0.13: 1$ \\
\hline September & $1.22 \pm 0.31: 1$ & $1.48 \pm 0.25: 1$ & & \\
\hline October & $1.73 \pm 0.44: 1$ & $1.48 \pm 0.20: 1$ & & \\
\hline $\begin{array}{l}\text { Mean } \pm 0.95 \\
\text { confidence interval }\end{array}$ & $1.09 \pm 0.29: 1$ & $1.47 \pm 0.08: 1$ & $0.45 \pm 0.20: 1$ & $1.17 \pm 0.10: 1$ \\
\hline
\end{tabular}

*Blank spaces indicate that no survey was conducted during that time.

${ }^{\dagger}$ All fawns observed, divided by all does observed.

${ }^{\ddagger}$ Fawns observed with does, divided by does observed with fawns. 
female population accounted for fawn production in 1981 than in 1980. Yearlings no doubt accounted for most of the nonreproducing does, but some adults were probably nonreproductive given that ungulates commonly skip a year of reproduction under poor conditions (McCullough 1979). In general, it appears that the reproductive rate of NMI does was similar to or even higher than for does in other high-density herds.

\section{Mortality}

Hunting, as a mortality factor, was minor in our study because the last hunt was conducted in 1977. Some deer, mostly adult males, may have been taken by local mainland residents in the fall of 1979, 1980, and 1981. The number of deer taken in those 3 years was unknown, but probably constituted less than 5 percent of the prehunt population.

No quantitative data were available on prenatal (loss of shed ova or embryos) or neonatal (parturition to 4 weeks) fawn mortality. Some prenatal mortality probably occurs in all deer herds regardless of physical condition or productivity (Woolf and Harder 1979).

Winter mortality due to nutritional and thermal stress was by far the most important mortality factor affecting the NMI herd during the period of study. Large-scale surveys of dead deer are enormously difficult to conduct (Woolf and Harder 1979; Karns 1980). Nonetheless, estimates of winter mortality are essential for population studies in northern areas.

Three-hundred-sixteen carcasses were found in areas that were completely searched in 1980. The carcasses of five deer believed to have died between 1977 and 1980 were located on $2540-\times 1,000$-m plots searched in 1981, resulting in an estimate of 260 \pm 182 carcasses present in areas not sampled or searched by other methods (table 12).

Of 482 deer carcasses examined, 76.8 percent died in the winter of 1977-78, 7.0 percent in 1978-79, and 16.2 percent in 1979-80. Applying these proportions to the total estimated number of carcasses, we arrived at an estimated winter mortality of $882 \pm 168$ in 1977-78, $81 \pm 15$ in 1978-79, and $186 \pm 36$ in 1979-80.

Fifty-three carcasses from the winter of 1980-81 were located on dead deer surveys conducted in June 1981 (table 13). Two-hundred-five carcasses from the winter of 1981-82 were located on dead deer surveys conducted in May 1982 (table 14). Winter mortality between 1977 and 1981 is summarized in table 15. Carcass density estimates ranged from a high of 26.7 per $\mathrm{km}^{2}$ in $1981-82$ to a low of 1.4 per $\mathrm{km}^{2}$ in $1978-79$. By comparison, large-scale dead deer surveys conducted on the mainland adjacent to NMI by Michigan Department of Natural Resources personnel estimated 1977-78 and 1978-79 winter losses at approximately 1.0 and 2.2 per $\mathrm{km}^{2}$ respectively (Burgoyne and Moss 1979).

The sex and age structure of winter-killed deer on NMI is presented in table 16. Chi-square tests indicated no significant differences $(P>0.05)$ in age structure between male and female winter-killed deer from the winters of 1978-79 and 1980-81. However, significant differences $(P<0.001)$ were found in the age structure of male and female carcasses from the winters of 1977-78 and 1981-82. In 1977-78, females had a much higher proportion of older deer ( 8.5 or more years) and a lower proportion of fawns than males. In 1981-82 males and females had similar proportions of fawns. 
TABLE 12. NUMBER OF WINTER-KILLED WHITE-TAILED DEER CARCASSES ESTIMATED BY CENSUS METHOD FOR THE WINTERS OF 1977-78, 1978-79, AND 1979-80

\begin{tabular}{|c|c|c|c|}
\hline Area & Area searched & Carcasses found & Total carcasses* \\
\hline & $b a$ & & \\
\hline Line-transect ${ }^{\dagger}$ & 174.4 & 71 & 504 \\
\hline Old Baldy & 16.2 & 10 & $27 \pm 15$ \\
\hline Feeding station & 44.0 & 15 & $37 \pm 16$ \\
\hline Northwest corner & 12.8 & 16 & $43 \pm 6$ \\
\hline 1981 plot sample & 100.0 & 5 & $260 \pm 182$ \\
\hline Complete search & 138.9 & 278 & 278 \\
\hline Miscellaneous $^{\ddagger}$ & 0 & 87 & 0 \\
\hline Total & 486.3 & 482 & $1,149 \pm 219$ \\
\hline
\end{tabular}

*Mean \pm 0.95 confidence interval.

${ }^{\dagger}$ Regression correction from Anderson and Pospahala (1970).

${ }^{\ddagger}$ Carcasses located in sampled areas but not on plots, transects, or areas completely searched. These carcasses were not used to compute estimates.

TABLE 13. NUMBER OF WINTER-KILLED WHITE-TAILED DEER CARCASSES ESTIMATED BY CENSUS METHOD FOR THE WINTER OF 1980-81

\begin{tabular}{lccc}
\hline \hline Area & Area searched & Carcasses found & Estimated total carcasses* \\
\hline & $b a$ & & \\
1981 plot sample & 100.0 & 4 & $221 \pm 221$ \\
Complete search & 129.0 & 40 & 40 \\
Miscellaneous $^{\dagger}$ & 0 & 9 & 0 \\
Total & 229 & 53 & $261 \pm 221$ \\
\hline
\end{tabular}

*Mean \pm 0.95 confidence interval.

${ }^{\dagger}$ Carcasses located in sampled areas but not on plots or areas completely searched. The carcasses were not used to compute estimates.

TABLE 14. NUMBER OF WINTER-KILLED WHITE-TAILED DEER CARCASSES ESTIMATED BY CENSUS METHOD FOR THE WINTER OF 1981-82

\begin{tabular}{lccc}
\hline \hline Area & Area searched & Carcasses found & Estimated total carcasses* \\
\hline & $b a$ & & \\
1982 plot sample & 75 & 19 & $1,438 \pm 837$ \\
Complete search & 106 & 147 & 147 \\
Miscellaneous $^{\dagger}$ & 0 & 39 & 0 \\
Total & 181 & 205 & $1,585 \pm 837$ \\
\hline
\end{tabular}

*Mean \pm 0.95 confidence interval.

${ }^{\dagger}$ Carcasses located in sampled areas but not used to compute estimates. 

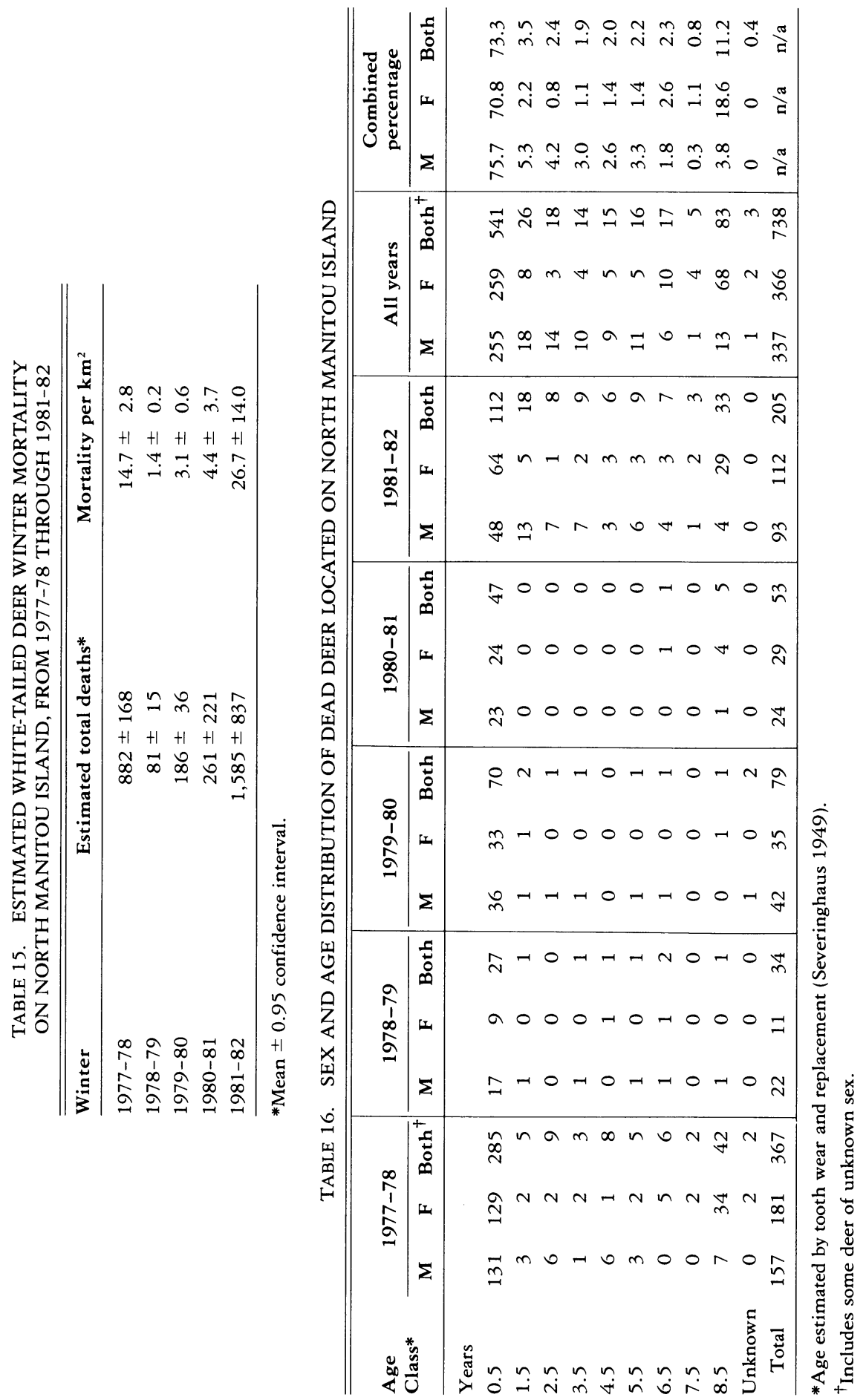
Females again accounted for a higher proportion of older deer while males accounted for a higher proportion of younger deer, especially yearlings.

Males showed a significant difference $(P<0.001)$ in age structure from year to year. The winter counts of 1977-78 and 1980-81 showed more fawns than expected while the winter count of 1981-82 showed fewer fawns and more older males. No significant differences $(P>0.05)$ were indicated for the female carcass age structure from year to year.

When data for all years were combined, a highly significant difference was found between male and female carcass age structure. Females had a lower proportion of mortality than males in the fawn-to-5.5 age classes and higher mortality in the 6.5-to-8.5 age classes.

\section{Physical Condition}

The physical condition of 32 deer collected on NMI in October 1980 is summarized in table 17. The mean whole body weight was $24 \mathrm{~kg}$ for fawns and $51 \mathrm{~kg}$ for yearlings. Six adult females averaged $54 \mathrm{~kg}$, while two adult males averaged $80 \mathrm{~kg}$. No significant difference $(P>0.05)$ in body weight existed between sexes in the yearling and fawn classes. However, adult males weighed significantly more than adult females. Adult males weighed more than yearling males $(P<0.05)$, whereas yearling and adult female weights were similar.

Although not significant $(P>0.05)$, the kidney fat index (KFI) and marrow fat (MF) were higher for females than for males in the fawn and yearling age classes, and higher for males in the adult age class. Mean KFI and MF values for fawns were lower than for yearlings and adults $(P<0.05)$.

Field-dressed weight of fawns and yearlings and yearling antler size were the primary indices used to assess herd condition. Comparative data of these standardized measurements are widely available in the literature (Woolf and Harder 1979) and are commonly used as criteria to evaluate herd condition (Klein 1970). The mean dressed weights

TABLE 17. PHYSICAL CONDITION OF DEER COLLECTED IN 1980 ON NORTH MANITOU ISLAND

\begin{tabular}{|c|c|c|c|c|c|c|c|}
\hline \multirow[b]{2}{*}{ Age } & \multirow[b]{2}{*}{ Sex } & \multirow{2}{*}{$\begin{array}{l}\text { Number } \\
\text { collected }\end{array}$} & \multicolumn{2}{|c|}{ Whole body weight } & \multirow{2}{*}{$\begin{array}{l}\text { Mean } \\
\text { KFI* }\end{array}$} & \multirow{2}{*}{$\begin{array}{c}\text { Mean } \\
\text { MF }^{\dagger}\end{array}$} & \multirow{2}{*}{$\begin{array}{c}\text { Mean antler } \\
\text { beam diameter }\end{array}$} \\
\hline & & & Mean & Range & & & \\
\hline & & &  & 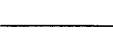 & & & \\
\hline \multirow{2}{*}{0.5} & $\mathrm{~F}$ & 3 & 24 & $19-27$ & 71.3 & 54.3 & - \\
\hline & M & 11 & 24 & $17-31$ & 45.8 & 51.5 & - \\
\hline \multirow{2}{*}{1.5} & $\mathrm{~F}$ & 2 & 51 & $47-55$ & 170.0 & 67.0 & - \\
\hline & M & 8 & 51 & $40-62$ & 122.7 & 65.3 & $12.9^{\ddagger}$ \\
\hline \multirow{2}{*}{ Adult } & $\mathrm{F}$ & 6 & 54 & $47-57$ & 88.5 & 70.2 & - \\
\hline & M & 2 & 80 & $65-94$ & 115.0 & 72.5 & $25.5^{5}$ \\
\hline
\end{tabular}

*Kidney fat index (Riney 1955).

${ }^{\dagger}$ Percent mandible fat (Friedrich and Burgoyne 1980).

${ }^{\ddagger}$ Includes one sublegal deer (antlers 3 inches long).

${ }^{5}$ Measurements of only one male were available. 
of deer by age and sex classes in a few northern areas of the United States are summarized in table 18. A subjective evaluation of general herd condition as reported by the authors was included. The account of herd condition on NMI between 1971 and 1977 was based on personal communications with D. A. Arnold of the Michigan Department of Natural Resources.

Weight of fawns is a useful indicator of physical condition in a deer herd because fawn weight reflects environmental conditions in the current year (Kirkpatrick et al. 1976). Both male and female fawns on NMI weighed less than fawns in other areas (table 18). The fawn weight of $22 \mathrm{~kg}$ for 1971 through 1977 decreased to $19 \mathrm{~kg}$ for 1980, possibly because of the 1977 termination of the winter feeding program. Weights of fawns collected from herds in good condition were substantially higher than those from poor-condition herds, especially NMI deer. For instance, NMI fawns weighed 69 percent as much as fawns collected on South Fox Island (Palmer and King 1970). Deer on South Fox Island were not supplementally fed.

North Manitou Island yearlings were similar in weight to yearlings from other poor-condition herds and lighter than yearlings from good-condition herds (table 18). Differences in weights were more pronounced among male yearlings than among female yearlings. Male yearlings on NMI weighed 77 percent as much as those on South Fox Island, while NMI female yearlings weighed 91 percent as much as South Fox Island female yearlings (Palmer and King 1970). However, only two yearling females were collected on NMI in 1980, so a valid comparison is impossible.

TABLE 18. MEAN FIELD-DRESSED WEIGHTS (SAMPLE SIZE IN PARENTHESES) BY AGE AND SEX CLASS FOR DEER IN THE NORTHERN UNITED STATES

\begin{tabular}{|c|c|c|c|c|c|c|c|}
\hline \multirow[b]{3}{*}{ Area } & \multirow{3}{*}{$\begin{array}{c}\text { Herd } \\
\text { condition* }\end{array}$} & \multicolumn{6}{|c|}{ Field-dressed weight } \\
\hline & & \multicolumn{2}{|c|}{ Fawns } & \multicolumn{2}{|c|}{ Yearlings } & \multicolumn{2}{|c|}{ Adults } \\
\hline & & $\mathbf{M}$ & $\mathbf{F}$ & $\mathbf{M}$ & $\mathbf{F}$ & $\mathbf{M}$ & $\mathbf{F}$ \\
\hline $\begin{array}{l}\text { North Manitou Island }{ }^{\dagger} \\
\text { (This study, 1980) }\end{array}$ & Poor & $\begin{array}{c}19 \\
(11)\end{array}$ & $\begin{array}{l}19 \\
(3)\end{array}$ & $\begin{array}{l}40 \\
(8)\end{array}$ & $\begin{array}{l}40 \\
(2)\end{array}$ & $\begin{array}{l}62 \\
(2)\end{array}$ & $\begin{array}{l}42 \\
(6)\end{array}$ \\
\hline $\begin{array}{l}\text { North Manitou Island } \\
\text { (MDNR Game Breeder } \\
\text { Reports 1971-77) }\end{array}$ & Poor & $\begin{array}{r}22^{\ddagger} \\
(83)\end{array}$ & $-\ddagger$ & $-s$ & $-s$ & $\begin{array}{r}54^{5} \\
(726)\end{array}$ & $\begin{array}{r}44^{5} \\
(391)\end{array}$ \\
\hline $\begin{array}{l}\text { Beaver Island } \\
\text { (Duvendeck 1968) }\end{array}$ & Poor & $\begin{array}{c}22 \\
(22)\end{array}$ & $\begin{array}{c}21 \\
(15)\end{array}$ & $\begin{array}{l}39 \\
(18)\end{array}$ & $\begin{array}{l}38 \\
(8)\end{array}$ & $\begin{array}{l}59 \\
(24)\end{array}$ & $\begin{array}{c}47 \\
(38)\end{array}$ \\
\hline $\begin{array}{l}\text { Rachelwood, Pennsylvania } \\
\text { (Woolf and Harder 1979) }\end{array}$ & Poor & $\begin{array}{c}24 \\
(194)\end{array}$ & $\begin{array}{c}23 \\
(187)\end{array}$ & $\begin{array}{c}46 \\
(225)\end{array}$ & $\begin{array}{c}38 \\
(137)\end{array}$ & $\begin{array}{c}59 \\
(300)\end{array}$ & $\begin{array}{c}47 \\
(314)\end{array}$ \\
\hline $\begin{array}{l}\text { Bois Blanc Island } \\
\text { (Duvendeck 1968) }\end{array}$ & Poor & $\begin{array}{c}24 \\
(15)\end{array}$ & $\begin{array}{c}23 \\
(23)\end{array}$ & $\begin{array}{l}38 \\
(14)\end{array}$ & $\begin{array}{l}37 \\
(9)\end{array}$ & $\begin{array}{l}53 \\
(49)\end{array}$ & $\begin{array}{c}44 \\
(54)\end{array}$ \\
\hline $\begin{array}{l}\text { South Fox Island } \\
\text { (Palmer and King 1970) }\end{array}$ & Good & $\begin{array}{c}28 \\
(46)\end{array}$ & $\begin{array}{c}27 \\
(30)\end{array}$ & $\begin{array}{c}52 \\
(54)\end{array}$ & $\begin{array}{c}44 \\
(25)\end{array}$ & $\begin{array}{c}75 \\
(69)\end{array}$ & $\begin{array}{c}47 \\
(48)\end{array}$ \\
\hline
\end{tabular}

*As described by author.

${ }^{\dagger}$ Dressed weight equals whole body weight/1.28 (Harder 1980).

¥Sexes combined.

${ }^{5}$ Yearlings and adults combined. 
Deer in most of the studies listed in table 18 were collected either at the same time of year as those collected on NMI or they were collected later. Had the deer on NMI been collected later in the year (i.e., November through January), the weight differences between NMI deer and deer from other herds might have been more pronouncedNMI deer have inadequate winter food, and lose weight throughout the winter (Kirkpatrick et al. 1976; Warren et al. 1981).

Antler size of NMI male yearlings was small relative to that of other herds. The mean beam diameter of the seven legal yearlings collected was $13.5 \mathrm{~mm}$, and the mean number of points was 2.0 per deer. The mean beam diameter of 2,866 deer examined in northern lower Michigan in 1980 was $19.1 \mathrm{~mm}$, and the antlers averaged 4.2 points (Burgoyne, Meister, and Alexander 1981). Fourteen yearlings (including ten sublegal spikes) collected on Bois Blanc Island in 1967 had an average beam diameter of 14.5 $\mathrm{mm}$ and 2.2 points per deer (Duvendeck 1968).

The small sample size of adult males (only two) precluded comparisons, but on the basis of observations made during direct counts, adult males on NMI had substantially smaller antlers than did adult males on the adjacent mainland.

\section{Parasite Burdens}

Five helminth species and several Coccidia species were found in the 32 deer that we examined (table 19). There were no significant differences in the occurrence of adult stages of brainworms between fawns, yearlings, and adults. Larval brainworms produced in the deer host would not be expected in the feces of fawns. Trichuris spp. and Nematodirus spp. occurred respectively in 57.1 and 7.1 percent of the fawns examined, while none of the yearling or adult deer feces we examined contained these parasites. Coccidia spp. occurred in eleven fawns ( 78.6 percent), one yearling (10 percent), and two adults (25 percent). There were no significant differences in occurrence of Capillaria spp. and Strongyles between fawns, yearlings, and adults $(P>0.05)$.

No trypanosomes, filarial worms (foot worms and abdominal worms), cestodes (intestinal tapeworms or visceral cystcerci), trematodes (liver flukes), lungworms, nosebots, piroplasms, or ectoparasites were found in any of the deer examined. Several of the tongue samples contained sarcocysts.

TABLE 19. OCCURRENCE OF PARASITES IN WHITE-TAILED DEER COLLECTED IN 1980

\begin{tabular}{|c|c|c|c|c|c|c|c|c|}
\hline \multirow[b]{4}{*}{ Age } & \multirow{4}{*}{$\begin{array}{c}\text { Sample } \\
\text { size }\end{array}$} & \multicolumn{7}{|c|}{ Percentage of occurrence } \\
\hline & & \multirow{2}{*}{\multicolumn{2}{|c|}{$\frac{\text { In brain }}{\text { Parelaphostrongylus }}$}} & \multicolumn{5}{|c|}{ In feces } \\
\hline & & & & \multirow{2}{*}{$\begin{array}{l}\text { Trichuris } \\
\text { spp. }\end{array}$} & \multirow{2}{*}{$\begin{array}{c}\text { Coccida } \\
\text { spp. }\end{array}$} & \multirow{2}{*}{$\begin{array}{c}\text { Capillaria } \\
\text { spp. }\end{array}$} & \multirow{2}{*}{$\begin{array}{l}\text { Strongyles } \\
\text { spp. }\end{array}$} & \multirow{2}{*}{$\begin{array}{l}\text { Nematodirus } \\
\text { spp. }\end{array}$} \\
\hline & & Adults & Larvae & & & & & \\
\hline years & & ---- & --- & ---- & $\%---$ & ----- & ----- & ---- \\
\hline 0.5 & 14 & 64.0 & 0.0 & 57.1 & 78.6 & 14.3 & 50.0 & 7.1 \\
\hline 1.5 & 10 & 80.0 & 80.0 & 0.0 & 10.0 & 10.0 & 70.0 & 0.0 \\
\hline Adult & 8 & 75.0 & 75.0 & 0.0 & 25.0 & 0.0 & 50.0 & 0.0 \\
\hline Total & 32 & 71.9 & 43.8 & 25.0 & 43.8 & 9.4 & 56.3 & 3.1 \\
\hline
\end{tabular}


Wildlife disease biologist John Stuht of the Michigan Department of Natural Resources judged the deer from NMI to be remarkably free of diseases and parasites (pers. comm.). Except for the brainworm, the parasite burdens were lower than would have been expected in a similar group of mainland deer.

\section{Habitat Relationships}

\section{Forage Availability and Utilization}

Browse surveys showed that American beech (Fagus grandifolia) was by far the predominant species (table 20). When all habitats were combined, beech constituted 96.6 percent of the available hardwood twigs (table 21). Rosa spp. was the most abundant twig in open fields, whereas cherry (Prunus) was most abundant in the conifer habitat type.

The open field areas contained 15,167 $\pm 17,887$ common juniper twigs per ha and $7,450 \pm 29,083$, or 49.1 percent of these, were browsed in the winter of 1980-81. Common juniper estimates were not used to compute values in tables 20 or 21 because of biases in comparing hardwood and conifer twigs (King 1970). Other than common juniper in open fields, no coniferous twigs were observed on the 200 plots examined. King did not count twigs of coniferous species, but reported $139.3 \mathrm{~kg}$ per ha of ground hemlock (Taxus canadensis) in the northern hardwood forest type of Garden Island, Michigan.

TABLE 20. PRODUCTION AND UTILIZATION OF HARDWOOD TWIGS BY HABITAT TYPE IN 1981

\begin{tabular}{|c|c|c|c|c|c|c|c|c|c|c|}
\hline \multirow[b]{3}{*}{ Browse species } & \multicolumn{10}{|c|}{ Habitat type } \\
\hline & \multicolumn{2}{|c|}{$\begin{array}{l}\text { Northern } \\
\text { hardwoods }\end{array}$} & \multicolumn{2}{|c|}{$\begin{array}{l}\text { Selective } \\
\text { cut }\end{array}$} & \multicolumn{2}{|c|}{$\begin{array}{l}\text { Open } \\
\text { field }\end{array}$} & \multicolumn{2}{|c|}{ Conifer } & \multicolumn{2}{|c|}{ Total } \\
\hline & $\%$ av** & $\%$ ut. ${ }^{\dagger}$ & $\%$ av. & $\%$ ut. & $\%$ av. & $\%$ ut. & $\%$ av. & $\%$ ut. & $\%$ av. & $\%$ ut. \\
\hline $\begin{array}{l}\text { American beech } \\
\quad(\text { Fagus grandifolia })\end{array}$ & 97.4 & 13.2 & 97.0 & 13.4 & 12.1 & 76.7 & 29.0 & 42.8 & 96.6 & 13.4 \\
\hline $\begin{array}{l}\text { Sugar maple } \\
\qquad(\text { Acer saccharum })\end{array}$ & 2.4 & 26.6 & 0.3 & 11.6 & 0.0 & 0.0 & 2.2 & 0.0 & 1.0 & 22.2 \\
\hline $\begin{array}{l}\text { Wild cherry } \\
\text { (Prunus spp.) }\end{array}$ & 0.1 & 0.0 & $<0.1$ & 0.0 & 0.0 & 0.0 & 63.8 & 57.0 & 0.3 & 47.4 \\
\hline $\begin{array}{r}\text { Other maples } \\
\text { (Acer spp.) }\end{array}$ & 0.1 & 0.0 & 0.1 & 100.0 & 0.0 & 0.0 & 2.2 & 0.0 & 0.1 & 69.6 \\
\hline $\begin{array}{l}\text { Rose } \\
\qquad(\text { Rosa spp.) }\end{array}$ & 0.0 & 0.0 & 2.3 & 26.7 & 87.9 & 35.0 & 0.0 & 0.0 & 1.8 & 27.8 \\
\hline $\begin{array}{l}\text { Birch } \\
\text { (Betulaceae) }\end{array}$ & 0.0 & 0.0 & $<0.1$ & 100.0 & 0.0 & 0.0 & 0.0 & 0.0 & $<0.1$ & 100.0 \\
\hline $\begin{array}{l}\text { Berries } \\
\qquad(\text { Rubus spp.) }\end{array}$ & 0.0 & 0.0 & 0.1 & 100.0 & 0.0 & 0.0 & 2.8 & 51.6 & 0.1 & 95.9 \\
\hline
\end{tabular}

*Percentage of all available twigs.

${ }^{\dagger}$ Percentage of twigs of that species browsed (utilized). 
TABLE 21. RESULTS OF A HARDWOOD TWIG COUNT SURVEY IN 1981

\begin{tabular}{|c|c|c|c|}
\hline Habitat type & $\begin{array}{l}\text { Number of } \\
\text { twigs per ha* }\end{array}$ & $\begin{array}{c}\text { Number of } \\
\text { browsed twigs per ha* }\end{array}$ & $\begin{array}{l}\text { Percentage } \\
\text { browsed }\end{array}$ \\
\hline $\begin{array}{l}\text { Northern } \\
\text { hardwoods }\end{array}$ & $\begin{array}{l}20,434 \\
(8,249)\end{array}$ & $\begin{array}{c}2,766 \\
(1,327)\end{array}$ & 13.5 \\
\hline $\begin{array}{l}\text { Selective-cut } \\
\text { northern hardwoods }\end{array}$ & $\begin{array}{l}111,966 \\
(20,810)\end{array}$ & $\begin{array}{l}15,633 \\
(5,145)\end{array}$ & 14.0 \\
\hline Open field & $\begin{array}{c}2,333 \\
(3,389)\end{array}$ & $\begin{array}{r}924 \\
(1,370)\end{array}$ & 39.6 \\
\hline Conifer & $\begin{array}{c}7,651 \\
(5,545) \\
\end{array}$ & $\begin{array}{c}3,850 \\
(2,793) \\
\end{array}$ & 50.3 \\
\hline All types ${ }^{\dagger}$ & $\begin{array}{l}43,986 \\
(7,423)\end{array}$ & $\begin{array}{c}6,170 \\
(1,634)\end{array}$ & 14.0 \\
\hline
\end{tabular}

*Mean, \pm 0.95 confidence interval given in parentheses.

${ }^{\dagger}$ Weighted by area in each type.

American beech constituted the major proportion of browsed twigs in the northern hardwoods and selective-cut northern hardwoods habitat types, and 92.4 percent of the total twigs browsed (table 20). Rose (Rosa) and sugar maple (Acer saccharum) constituted 3.6 and 1.7 percent of the twigs browsed, respectively. The availability and utilization columns in table 20 show that beech was the only woody species not browsed at a higher percentage than it occurred, indicating that beech was not a preferred browse species. It should be kept in mind that, other than beech, most of the twigs encountered were on very small plants or were on branches hanging down from large trees. Many of the twigs available in spring may not have been accessible to deer in the winter because of snow cover.

The distribution of hardwood twig biomass by species in each habitat type as determined by the 1981 vegetation survey correlates closely with the results from the spring twig survey. This was to be expected, since the data from both surveys were collected on the same plots. No estimates of common juniper biomass were available. Northern white cedar, which was common in the overstory of the conifer areas, was not recorded on any of the plots sampled. In addition, no white cedar seedlings, saplings, or mature trees with foliage under $1.8 \mathrm{~m}$ were found on the island. Northern white cedar is a highly nutritious and preferred deer food (Ullrey et al. 1968; Beals, Gottam, and Vogl 1960; Jensen 1982).

The abundance of deciduous tree and shrub leaves (table 22) correlated to the abundance of twigs (table 20). American beech was the dominant species in the northern hardwood and selective-cut habitat types. Rose was the dominant woody plant in the open field type, whereas cherry dominated the conifer type. When all habitats were combined, beech accounted for 96.8 percent of the leaf biomass. Production of deciduous leaves was highest in the selective-cut habitat type (table 22) followed by northern hardwood, conifer, and open field types. Production of leaves in all habitat types averaged to $81.1 \pm 29.7 \mathrm{~kg}$ per ha.

Deer removed deciduous leaves at rates of $0.40 \mathrm{~kg}$ per ha in the conifer habitat, 0.28 $\mathrm{kg}$ per ha in selective-cut, $0.05 \mathrm{~kg}$ per ha in northern hardwoods, and $0 \mathrm{~kg}$ per ha in open fields. Overall removal was $0.11 \mathrm{~kg}$ per ha, or 0.14 percent. Two of the fifteen 
TABLE 22. PRODUCTION AND UTILIZATION OF DECIDUOUS LEAF BIOMASS BY HABITAT TYPE IN JULY 1981

\begin{tabular}{|c|c|c|c|c|c|c|c|c|c|c|}
\hline \multirow[b]{3}{*}{ Browse species } & \multicolumn{10}{|c|}{ Habitat type } \\
\hline & \multicolumn{2}{|c|}{$\begin{array}{l}\text { Northern } \\
\text { hardwoods }\end{array}$} & \multicolumn{2}{|c|}{$\begin{array}{l}\text { Selective } \\
\text { cut }\end{array}$} & \multicolumn{2}{|c|}{$\begin{array}{l}\text { Open } \\
\text { field }\end{array}$} & \multicolumn{2}{|c|}{ Conifer } & \multicolumn{2}{|c|}{ Total } \\
\hline & \%av.* & $\%$ ut. $^{\dagger}$ & $\%$ av. & \% ut. & $\%$ av. & $\%$ ut. & $\%$ av. & $\%$ ut. & $\%$ av. & \% ut. \\
\hline $\begin{array}{l}\text { American beech } \\
\qquad \text { (Fagus grandifolia) }\end{array}$ & 98.5 & 0.1 & 98.2 & 0.1 & 0.0 & 0.0 & 4.5 & 0.0 & 96.8 & 0.1 \\
\hline $\begin{array}{l}\text { Sugar maple } \\
\text { (Acer saccharum) }\end{array}$ & 1.1 & 2.3 & 0.3 & 2.5 & 0.0 & 0.0 & 0.2 & 0.0 & 0.5 & 2.5 \\
\hline $\begin{array}{l}\text { Wild cherry } \\
\text { (Prunus spp.) }\end{array}$ & 0.3 & 0.0 & 0.1 & 1.0 & 25.0 & 0.0 & 94.9 & 2.4 & 0.6 & 1.8 \\
\hline $\begin{array}{l}\text { Mountain maple } \\
\quad(\text { Acer spicatum })\end{array}$ & 0.1 & 0.0 & 0.1 & 0.0 & 0.0 & 0.0 & 0.3 & 0.0 & 0.1 & 0.0 \\
\hline $\begin{array}{l}\text { Rose } \\
\quad \text { (Rosa spp.) }\end{array}$ & 0.0 & 0.0 & 1.1 & 0.0 & 75.0 & 0.0 & 0.0 & 0.0 & 0.9 & 0.0 \\
\hline $\begin{array}{l}\text { Birch } \\
\quad \text { (Betulaceae) }\end{array}$ & 0.0 & 0.0 & 0.2 & 0.0 & 0.0 & 0.0 & 0.1 & 0.0 & 0.1 & 0.0 \\
\hline
\end{tabular}

*Percentage of available leaf biomass.

${ }^{\dagger}$ Percentage of leaf biomass removed.

plots measured in the conifer type occurred on steep, wind-thrown slopes. Woody plants in these areas were protected from winter browsing because snow made them inaccessible. In the snow-free season, however, deer were able to get to some of the forage. Seasonal variation in browse pressure would account for the high production and utilization in the conifer habitat type.

Beech foliage was consumed in a lower proportion than its abundance while sugar maple and cherry were preferred when habitat types were combined. No removal of mountain maple, red maple (Acer rubrum), rose, and Betulaceae foliage was observed on any of the plots, but these species occurred at very low densities. Browsing of woody twigs by deer during the summer was not recorded on sample plots or observed elsewhere on the island.

The production and utilization of herbaceous vegetation is presented in table 23 . Woody plant seedlings that had just germinated and were in their first year of growth were included in herbaceous biomass measurements because the lack of woody structure gave them a herbaceous-like character. With all habitats combined, $48.1 \pm 15.2 \mathrm{~kg}$ per ha of herbaceous material were produced, and $5.3 \mathrm{~kg}$ per ha (11.0 percent) of the material were removed by deer. Spotted knapweed (Centaurea maculosa) was the most abundant herbaceous plant (22.1 percent of biomass) and constituted the largest proportion of the herbaceous material removed (62.7 percent). Houndstongue (Cynoglossum officinale) was the second most abundant plant (14.5 percent), but was not browsed. Sugar maple was the most abundant woody seedling (11.5 percent) and was also the most heavily browsed (19.5 percent). No estimate of graminid use by deer in summer was available.

Total plant production within $1.8 \mathrm{~m}$ of the ground is summarized in table 24 . The graminid group was the most abundant in all habitats except the selective-cut hardwood. 
Fifty-three times more herbaceous material than deciduous leaves $(5.3$ versus $0.1 \mathrm{~kg}$ per ha) was removed from sample plots by deer on NMI (tables 22 and 23). We may not have noticed the removal of some deciduous leaves in some areas because of dense foliage, but even if observed leaf removal were tripled (to $0.3 \mathrm{~kg}$ per ha), herbaceous material would have been removed 18 times more than deciduous leaves. In spite of these low numbers, deer on NMI did forage on deciduous leaves when available, as

TABLE 23. PRODUCTION AND UTILIZATIOIN OF HERBACEOUS VEGETATION BIOMASS IN JULY 1981*

\begin{tabular}{|c|c|c|c|c|}
\hline \multirow[b]{2}{*}{ Plant } & \multicolumn{2}{|c|}{ Production } & \multicolumn{2}{|c|}{ Utilization } \\
\hline & kg per ha & Proportion & kg per ha & Proportion \\
\hline & & $\%$ & & $\%$ \\
\hline Centaurea maculosa & 10.46 & 22.1 & 3.34 & 62.7 \\
\hline Rumex acetosella & 5.38 & 11.4 & 0.13 & 2.4 \\
\hline Asclepias spp. & 4.81 & 10.2 & 0.03 & 0.6 \\
\hline Plantago spp. & 1.14 & 2.4 & 0.08 & 1.5 \\
\hline Hieracium spp. & 0.78 & 1.6 & 0.00 & 0.0 \\
\hline Potentilla spp. & 0.53 & 1.1 & $<0.01$ & $<0.1$ \\
\hline Rudbeckia birta & 0.31 & 0.6 & 0.12 & 2.2 \\
\hline Satureja vulgaris & 0.28 & 0.6 & 0.03 & 0.6 \\
\hline Hypericum perforatum & 0.22 & 0.5 & 0.00 & 0.0 \\
\hline Fern family & 5.45 & 11.5 & 0.18 & 3.4 \\
\hline Berteroa incana & 0.19 & 0.4 & 0.04 & 0.8 \\
\hline Tragopogon pratensis & 0.14 & 0.3 & $<0.01$ & $<0.01$ \\
\hline Chrysantbemum leucantbemum & 0.14 & 0.3 & 0.01 & 0.2 \\
\hline Fragaria spp. & 0.10 & 0.2 & 0.01 & 0.2 \\
\hline Linaria vulgaris & 0.08 & 0.2 & 0.00 & 0.0 \\
\hline Vicia cracca & 0.08 & 0.2 & 0.01 & 0.2 \\
\hline Arabis spp. & 0.03 & 0.1 & 0.00 & 0.0 \\
\hline Lepidium spp. & 0.03 & 0.1 & 0.00 & 0.0 \\
\hline Cynoglossum officinale & 6.86 & 14.5 & 0.00 & 0.0 \\
\hline Allium tricoccum & 0.70 & 1.5 & 0.00 & 0.0 \\
\hline Viola spp. & 0.56 & 1.2 & 0.06 & 1.1 \\
\hline Cirsium spp & 0.40 & 0.8 & 0.05 & 0.9 \\
\hline Rubus spp. & 0.16 & 0.3 & 0.03 & 0.6 \\
\hline Anaphalis margaritacea & 0.05 & 0.1 & 0.00 & 0.0 \\
\hline Veronica spp. & 0.08 & 0.2 & 0.00 & 0.0 \\
\hline Trillium spp. & 0.49 & 1.0 & 0.08 & 1.5 \\
\hline Monotropa uniflora & 0.09 & 0.2 & 0.04 & 0.8 \\
\hline Hydrocotyle americana & 0.06 & 0.1 & 0.00 & 0.0 \\
\hline Unknown & 0.65 & 1.4 & 0.00 & 0.0 \\
\hline \multicolumn{5}{|l|}{ Woody Seedlings } \\
\hline Acer saccharum & 5.43 & 11.5 & 1.04 & 19.5 \\
\hline Fagus grandifolia & 0.81 & 1.7 & $<0.01$ & 0.2 \\
\hline Prunus spp. & 0.37 & 0.8 & $<0.01$ & 0.2 \\
\hline Acer spp. & 0.17 & 0.3 & 0.02 & 0.4 \\
\hline Betulaceae & 0.03 & 0.1 & $<0.01$ & $<0.01$ \\
\hline Populus spp. & 0.02 & $<0.1$ & 0.0 & 0.0 \\
\hline $\begin{array}{l}\text { Total } \pm 0.95 \\
\text { confidence interval }\end{array}$ & $48.1 \pm 15.2$ & & 5.3 & \\
\hline
\end{tabular}

*Only plants that constituted $\geq 0.1$ percent availability. 





shown by the removal of foliage from fallen limbs. In some instances, the foliage of a large limb that had fallen to the ground in a storm was completely removed within 24 hours. It appears that deer on NMI preferred deciduous leaves, but so few leaves were available that they constituted a relatively small portion of the summer diet.

Although no estimates of graminid removal were available, our observations of feeding deer indicated that they consumed considerable amounts of grasses and sedges during the summer months. McCaffery, Tranetzki, and Piechura (1974) reported that grasses were important in the early and late summer diets of white-tailed deer in northern Wisconsin. Stormer and Bauer (1980), working with tame deer, found that grasses made up between 4.0 and 10.2 percent of the diet from June through August.

We believed that the summer vegetation survey provided a reasonable estimate of the summer food habits of NMI deer, but we may have underestimated the importance of some localized food sources. For instance, field observations indicated that deer foraged heavily on wild leek bulbs (Allium tricoccum) on the northern portion of the island. Leeks were patchy in distribution and only one plant was located on the sample plots. In some areas their density was high, as shown by the conspicuous holes left where deer had dug up the bulbs.

Aquatic vegetation was also utilized heavily by deer, but we made no quantitative estimates. Aquatic vegetation was available around the perimeters of Lake Manitou and Tamarack Lake and in a marsh in the Swenson clearing. Deer were observed foraging in the water in these places from late May to mid-October of 1980 and 1981. During evening hours, as many as 10 deer were observed foraging along the south shoreline of Lake Manitou. Individual deer were observed to forage for long periods (more than 30 minutes) and consume a variety of vegetation including bulrush (Scirpus spp.), cattail (Typha spp.), and sedge (Carex spp.).

\section{Rumen Botanical Composition}

The botanical composition of the contents of 13 fawn and 18 adult (including yearling) white-tailed deer rumina collected on NMI is given in table 25. Eighteen genera were identified in the 31 samples. The number of taxa ranged from 3 to 12 per rumen, and averaged 6.7. The mean identified fraction for all rumina was high $(88.1 \pm 3.5$ percent $)$, probably a result of the large proportion of the sample that consisted of easily identified fruits, fungi, and grasses.

Graminids, cherry and sugar maple leaves, apples (Malus domestica), and acorns (Quercus spp.) were important fall food items for both adults and fawns (table 25). Graminids were found in all rumina examined and comprised the highest percent aggregate volume of fawns and the third highest for adults. McCaffery, Tranetzki, and Piechura (1974) believed that grasses were critically important to deer in the spring and fall in northern Wisconsin. Grasses were present in 89 percent of 19 fall-collected rumina examined by McCaffery, Tranetzki, and Piechura and constituted 14 percent of the aggregate volume, results quite similar to ours. Coblentz (1970) and McCullough (1985) found that George Reserve deer relied heavily on grasses in the fall and early winter, and suggested that the importance of grasses was commonly underestimated.

The major portion of the sugar maple foliage consumed by NMI deer in the fall was believed to have been eaten from seedlings. Sugar maple seedlings constituted 11.5 percent of the herbaceous material eaten (table 23). Sugar maple was the most abundant mature tree species on NMI and accounted for more fallen limbs due to high 





winds or storms than any other species. These limbs might have provided substantial forage to deer in areas where wind damage was high.

Cherry foliage constituted only 0.8 percent of the herbaceous biomass (table 23) and 0.6 percent of the deciduous leaf biomass (table 22), yet was found in 29 of the 31 rumina examined and made up 17.6 and 19.5 percent of the aggregate volume of fawn and adult rumen contents, respectively. The large discrepancy between the availability and utilization of cherry foliage, together with the fact that most cherry leaves observed in the rumina were yellow, led to the conclusion that deer obtained a large portion of the cherry foliage by picking up fallen leaves off the forest floor.

White-tailed deer avidly consume apples, and consumed them when available on NMI (table 25). Apple orchards throughout NMI were frequented by deer. The rumen-content analysis might have been biased in that more deer were observed, and hence collected, in and around orchards. The degree of bias cannot be determined, because we do not know how far the deer travelled specifically to reach the orchards.

Although rumen contents were similar for adults and fawns, we did observe one important difference. Although apples occurred in 61.1 and 38.5 percent of the adult and fawn rumina, respectively, and made up 34.6 and 14.2 percent of the aggregate volume, the proportion of each age class collected within $500 \mathrm{~m}$ of an apple source was about equal (61 and 54 percent for adults and fawns, respectively). This difference in apple utilization may have resulted from two factors. First, because of their smaller size, fawns may not have been as efficient as adults at picking apples out of trees. Adults were commonly observed standing on their hind legs to feed on apples in trees, while fawns were rarely observed doing this. Second, agonistic behavior was common among deer, especially in areas where apple trees were few in number. Because fawns are lowest in the social hierarchy (Hirth 1977), they may have been excluded from feeding under trees when adults or yearlings were present.

Fawns may also have been excluded from feeding at other concentrated food sources, such as fallen limbs. Intraspecific competition in deer has been considered important in other studies. McCullough (1979) suggested that social dominance was quite important in terms of diet quality during the fall when the food supply was variable in quality and patchy in distribution. Klein and Olson (1960) observed adult dominance of fawns during periods of deep snow in Alaska, and believed this led to unusually heavy losses among fawns.

There may have been differences in forage utilization between male and female deer on NMI, as reported by McCullough (1985) and Beier (1987). However, the small sample sizes made comparisons impossible.

\section{Consumption of Alewives}

North Manitou Island deer consume considerable quantities of alewives (Alosa pseudobarengus) during the extensive, annual alewife dieoffs in Lake Michigan that typically occur between April and July (Case and McCullough 1987). We estimated that, when dead alewives were abundant, the average deer on NMI visited the beaches about three times a day and consumed from 30 to 50 percent of its daily rumen volume in alewives.

Because alewives are higher in digestible nutrients and sodium and lower in fiber than natural forages, we believe that NMI deer receive an enormous nutritional surge in spring and early summer, a critical growth period. This surge in nutrient quality and 
availability probably contributes significantly to population productivity, offsetting to some extent the debilitating effects of inadequate winter forage resources.

\section{Habitat Use}

The spring, summer, and fall habitats used by white-tailed deer on NMI were determined by observation on line-transect surveys. We made comparisons using density estimates in each habitat type, computed by the Kelker (1945) method. To allow comparisons between time periods and age classes, we converted the density estimates to percentages of the total density (the combined density in all habitats). If deer did not seek out or avoid certain habitat types (i.e., if they practiced random habitat selection), an equal proportion ( 33 percent) of deer would be expected in each type.

Adult deer avoided the northern hardwood forest habitat type in all months sampled (fig. 9). Highest use of the northern hardwoods type occurred in May and October. Open fields were highly preferred in July, August, and September of 1980. In 1981, open fields were preferred in June and July, but not in May. Deer use of the selectivecut northern hardwoods habitat was relatively stable throughout both field seasons, and the habitat was neither preferred nor avoided.

In August, September, and October 1980, fawns exhibited a strong preference for open fields and avoided forested habitats. In August 1981, however, fawns preferred the selective-cut forest type and avoided the northern hardwoods and open field types.

No information was available on the use of other habitat types, such as aquatic or conifer, because of the small amount of these types covered by our sampling routes. Our habitat utilization data probably reflect deer use as related to feeding activities, since most of the deer observed on the counts were feeding.
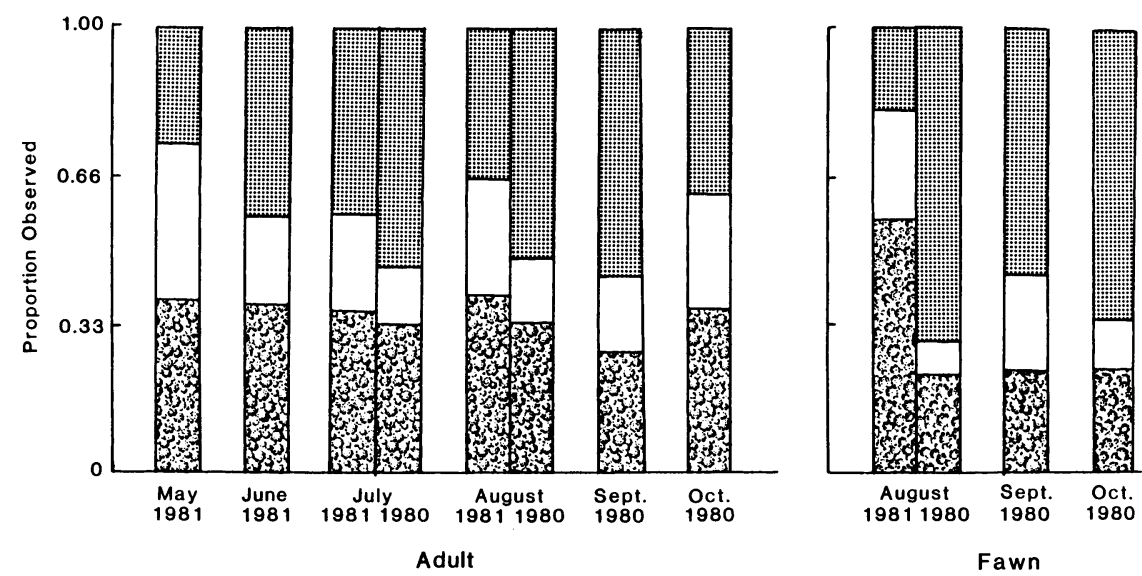

Month / Year

Northhern Hardwoods

Selective-cut N.Hdwds.

典 Open Field

Fig. 9. Proportions of adult and fawn deer observed in three habitat types by month and year (proportions adjusted to account for differential observability; see text for explanation). 
Limited information on winter use of habitats by NMI deer was obtained from observations made during winter visits to the island. National Park Service biologists visited NMI in January and February of 1981 and 1982. They travelled extensively on skis and observed deer and deer sign in all habitat types. Winter starvation occurred both years, and carcasses were found in all habitat types. Results from the 1981 twig survey also indicated that the deer were utilizing all habitat types during winter.

Winter concentration areas for the deer were determined from the distribution of dead deer found on carcass surveys and from winter observations (fig. 10). Pellet group distribution was not considered a reliable indicator of habitat usage (Neff 1968; Collins and Urness 1981), and therefore was not used. Although deer tended to concentrate in some areas of coniferous cover, the yarding observed in other northern areas of the white-tailed deer range did not occur on NMI.

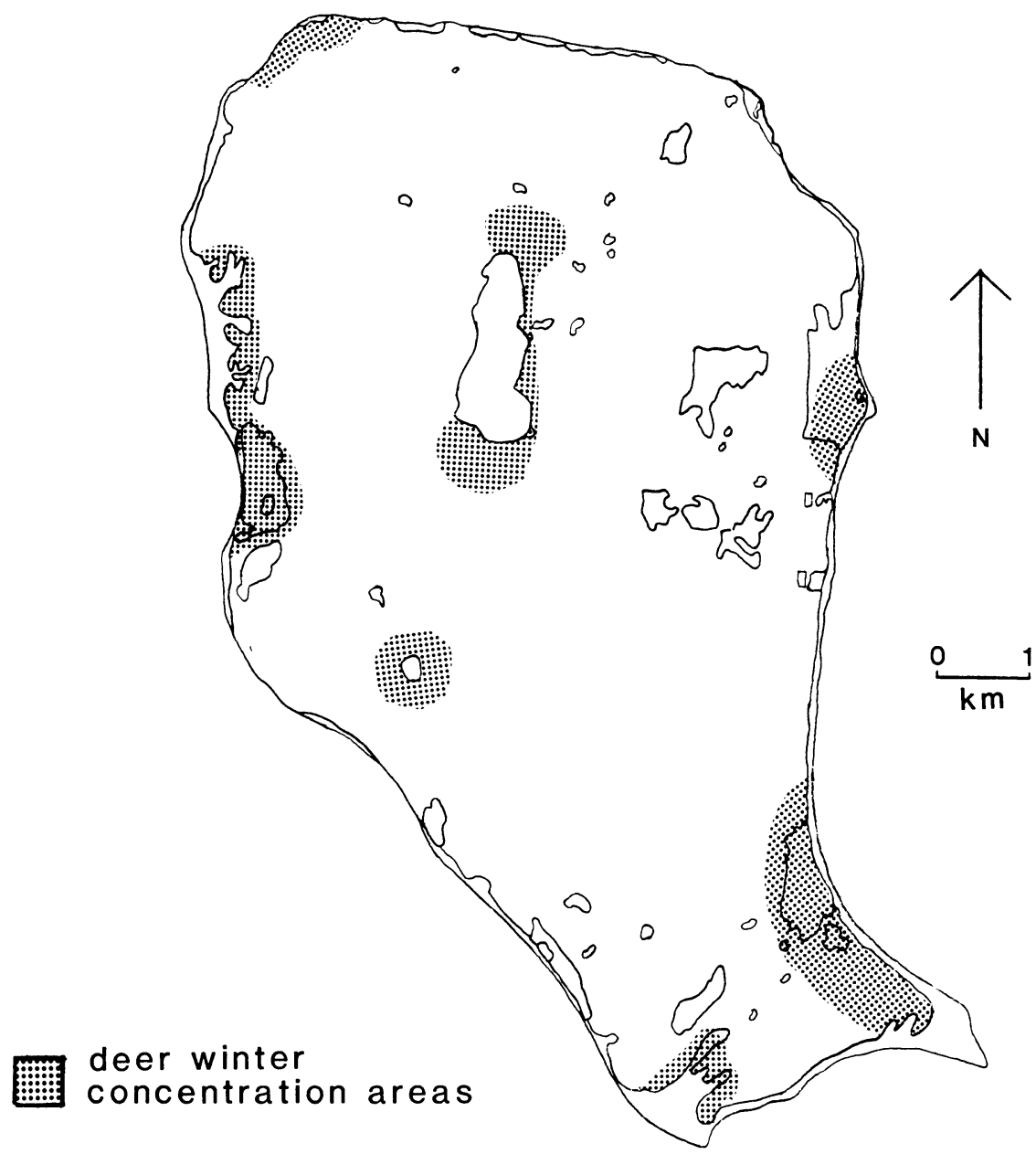

Fig. 10. White-tailed deer winter concentration areas, 1977 to 1982 . 
Studies of deer yarding in Michigan's Upper Peninsula and northern Minnesota have shown that deer may move considerable distances to occupy yards, and that they often remain in the yards under poor food conditions despite an abundance of browse in adjacent upland habitats (Verme 1965a, 1973; Nelson and Mech 1981; Robinson et al. 1982). Ozoga and Gysel (1972) reported that cold weather in early winter prompted deer to move to yards and that snow depth regulated their movement and habitat usage once in yards. The winter of 1980-81 was mild and the deer on NMI may not have been prompted to concentrate in yards. However, though the winter of 1981-82 was severe, deer were still observed in upland sites in February. Weather does not seem to account for the lack of yarding behavior in the NMI deer herd.

The lack of large, contiguous areas of coniferous cover probably explains the absence of yarding behavior. The largest coniferous area was less than 15 ha, and this mixed hardwood, balsam fir, eastern hemlock, and white cedar area seemed to be the preferred winter area for NMI deer.

\section{Vegetative Response to Deer Exclosure}

The production of deciduous leaves and twigs inside a 5- $\times 5$-m deer exclosure established in 1962 gives a useful indication of the long-term cumulative effects of deer browsing on vegetation. Total deciduous leaf production in the exclosure (table 26) was 4.6 times greater than production in the northern hardwood forest type that was subjected to deer browsing ( 124.7 versus $26.8 \mathrm{~kg}$ per ha). The relative species composition in the exclosure was quite different from that in the northern hardwood forest. Beech constituted 98.5 percent of the available deciduous leaf biomass in the northern hardwood forest (table 22), but only 1.6 percent in the exclosure. Conversely, sugar maple constituted 49.0 percent of the leaf biomass in the exclosure and 0.5 percent outside. Cherry also made up a higher proportion of the leaf biomass inside the exclosure than outside. The percent composition of mountain maple was about equal inside and outside the exclosure. As previously noted, deer preferred sugar maple and cherry foliage but avoided beech.

TABLE 26. PRODUCTION OF DECIDUOUS LEAVES AND TWIGS INSIDE THE DEER EXCLOSURE, AUGUST 1981*

\begin{tabular}{lrccr}
\hline \hline Plant & \multicolumn{2}{c}{ Leaves } & \multicolumn{2}{c}{ Twigs } \\
\hline & $k g / h a$ & $\%$ & $k g / h a$ & $\%$ \\
Fagus grandifolia & 2.0 & 1.6 & 0.2 & 1.4 \\
Acer saccharum & 61.1 & 49.0 & 6.4 & 43.9 \\
Prunus spp. & 4.8 & 3.8 & 1.0 & 6.8 \\
Acer spicatum & 0.3 & 0.2 & 0.04 & 0.3 \\
Betulaceae & 0.8 & 0.6 & 0.1 & 0.7 \\
Sambucus canadensis & 40.5 & 32.5 & 5.0 & 34.3 \\
Rubus spp. & 15.0 & 12.0 & 1.8 & 12.3 \\
Acer rubrum & 0.2 & 0.2 & 0.05 & 0.3 \\
\multicolumn{1}{c}{ Total } & 124.7 & 99.9 & 14.6 & 100.0 \\
\hline
\end{tabular}

*The exclosure was erected in 1962. 
Four species or taxonomic groups (American elder, red maple, Rubus spp., and Betulaceae) located on one or both of the plots inside the exclosure were not recorded on any of the 40 plots measured in the northern hardwood forest outside the exclosure. Two species occurring inside the exclosure (American elder and red maple) were not located on any of the 100 plots measured elsewhere on the island. American elder was the second most abundant species inside the exclosure, and constituted 32.5 percent of the leaf biomass below $1.8 \mathrm{~m}$. It should be noted that American elder specimens, although rare, were found in areas inaccessible to deer, such as cliff overhangs or blowdowns. This indicated that the seed source was present throughout the island. Rubus spp., absent on the 40 northern hardwood plots, accounted for 12.0 percent of the biomass inside the exclosure. Betulaceae and red maple each constituted less than 1 percent of the available biomass in the exclosure. The relative availability of twigs inside and outside the exclosure was similar to the availability of deciduous leaves (tables 21 and 26).

The distribution of basal diameters of beech, sugar maple, and cherry trees with foliage under $1.8 \mathrm{~m}$ in the northern hardwood and selective-cut northern hardwood forest types and in the deer exclosure are given in figure 11. The diameter distribution of beech on the uncut northern hardwood plots was typical of shade-tolerant species, with the smallest trees the most abundant and some specimens represented in most diameter classes. Sugar maple and cherry, on the other hand, showed no individuals over $3 \mathrm{~mm}$ basal diameter on any of the plots examined outside the exclosure.

In the selective-cut type, the stem densities of all species were higher than in the northern hardwood type, but the same general diameter distributions were observed (fig. 11). The higher stem density in the selective-cut type was to be expected, since the seedlings had less competition for light and nutrients than those in the uncut areas. No cherry trees with basal diameters greater than $3 \mathrm{~mm}$ were located on the 30 selectivecut plots, and no sugar maple stems greater than $6 \mathrm{~mm}$ were recorded. The stem density of sugar maple between 4 and $6 \mathrm{~mm}$ basal diameter was only 166 per ha. Sugar maple and cherry were the most abundant species, other than beech, in both the northern hardwood and the selective-cut northern hardwood forest types.

Some of the openings created by timber harvesting in the selective-cut forests ranged up to 2 ha in size. In addition, most of the areas classified in this habitat type had been cut less than 20 years prior to this study. Given the large opening size and the relatively short time since harvesting, one would expect to see an abundance of early successional species such as aspen, birch, and Rubus spp. Mature aspen and birch were observed in or near the selective-cut areas. Nevertheless, no reproduction of these species other than stump sprouting was observed on the vegetation plots or during other field work.

The basal diameter distribution in the deer exclosure was quite different than that in the forested habitats outside the exclosure. The total number of beech stems per ha was about equal in the exclosure and in the northern hardwood forest type. The distribution of beech by size class was, however, quite different. The largest beech diameter class inside the exclosure was 7 to $9 \mathrm{~mm}$, while the largest on the northern hardwood plots was 22 to $24 \mathrm{~mm}$. Sixty-two times more sugar maple stems were found inside the exclosure than in the northern hardwood forest type. The largest class of sugar maple in the exclosure was 13 to $15 \mathrm{~mm}$.

The combined sugar maple seedlings in all habitat types made up 11.5 percent of the herbaceous biomass, while beech seedlings constituted only 1.7 percent (table 23). 

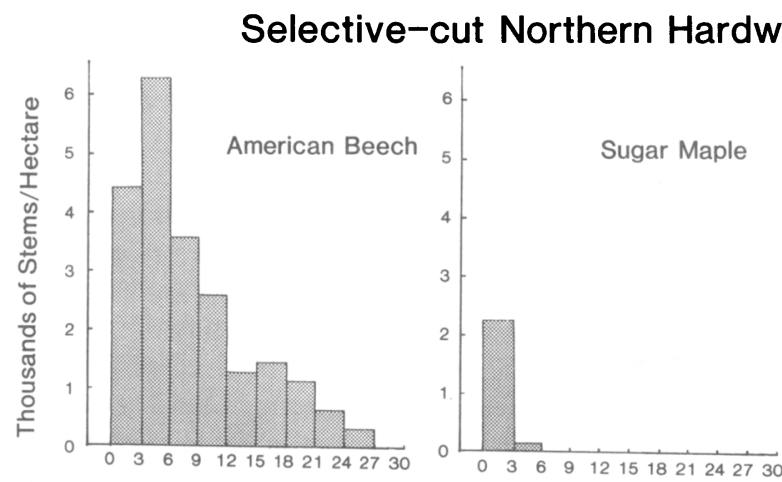

\section{oods}

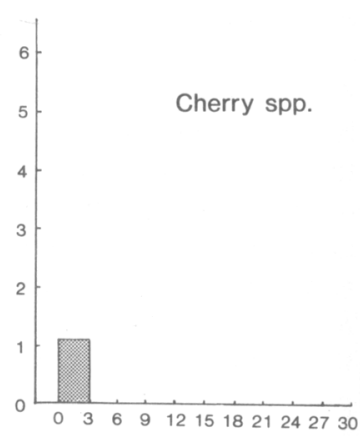

Basal Diameter Class ( $\mathrm{mm})$

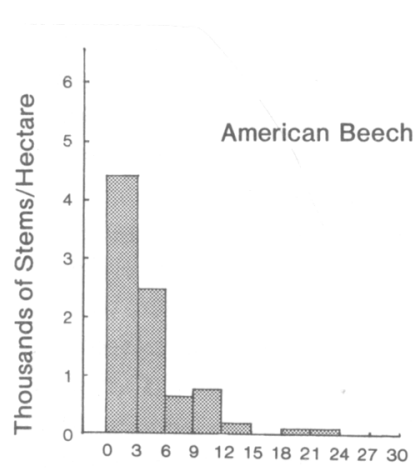

Northern Hardwoods
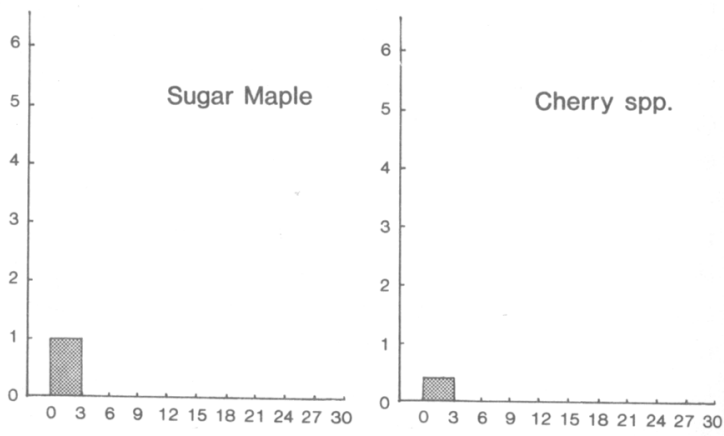

Basal Diameter Class ( $\mathrm{mm})$


\section{Basal Diameter Class ( $\mathrm{mm}$ )}

Fig. 11. Basal diameter ( $\mathrm{mm}$ ) distributions of woody plants in the northern hardwood forest habitat type, 1981 . 
Hence, the dominance of beech over other woody plants in the forest understory cannot be attributed to differential seedling survival in the first year after germination. This supports the conclusion that by selectively browsing, deer have caused the dominance of beech in the understory, suppressing the more preferred species.

The biomass and relative composition of grass and herbaceous vegetation in the forested habitats on NMI were also affected by deer feeding. Grass constituted 8.2 percent of the plant biomass in the exclosure and 38.3 percent in the northern hardwood forest type (table 24). Herbaceous vegetation constituted 31.9 percent of the biomass in the exclosure and only 19.5 percent in the northern hardwood type. Herbaceous biomass was five times greater inside the exclosure than in the northern hardwood forest, and was one and one-half times higher than in the selective-cut northern hardwood type. In a Pennsylvania study, fern and grass biomass expanded in areas where browsing or other factors prevented the development of tree seedlings and Rubus spp. that would normally have occupied the sites (Marquis 1981).

Viola spp. and Trillium spp. biomass (table 27) in the exclosure were measured at 52.0 and $21.0 \mathrm{~kg}$ per ha, respectively; in the northern hardwoods type, they measured 0.1 and $0.7 \mathrm{~kg}$ per ha. The mean dry weight of 41 Trillium spp. individuals collected on the northern hardwood plots was $0.06 \mathrm{~g}$, while the single Trillium spp. individual located on the plots inside the exclosure was $2.1 \mathrm{~g}$. The mean dry weight of 33 Viola spp. individuals in the northern hardwood type was $0.01 \mathrm{~g}$, while 73 individuals in the exclosure had a mean weight of $0.07 \mathrm{~g}$. Sugar maple seedling biomass was $1.4 \mathrm{~kg}$ per ha in the exclosure, compared to $5.9 \mathrm{~kg}$ per ha in the northern hardwood forest. Evidently, the increased competition of herbaceous material reduced the biomass of sugar maple seedlings in the exclosure.

Comparisons of protected vegetation in the exclosure and vegetation in browsed northern hardwood forest areas should be viewed with caution, since the exclosure represents only a single, small site, and microhabitat effects could account for some of the differences. However, the differences between vegetation inside and outside the exclosure were so dramatic that we felt the above comparisons were warranted.

\section{Old-Field Succession}

In approximately 30 old fields ranging in size from 1 to 43 ha, no new trees or shrubs were found, and a number of trees present in 1952 photos were absent in 1981 . There was no encroachment of the forest edge. By comparison, South Manitou Island aerial

TABLE 27. PRODUCTION OF HERBACEOUS VEGETATION ON A 1-M ${ }^{2}$ PLOT INSIDE THE DEER EXCLOSURE, AUGUST 1981

\begin{tabular}{lcc}
\hline \hline & \multicolumn{2}{c}{ Production } \\
\cline { 2 - 3 } Plant & kg per ha & Relative percentage \\
\hline Viola spp. & 52.0 & 69.9 \\
Trillium spp. & 21.0 & 28.2 \\
Acer saccharum (woody seedlings) & 1.4 & 1.9 \\
\cline { 2 - 3 } Total & 74.4 & 100.0 \\
\hline
\end{tabular}


photographs revealed that old fields on that island succeeded rapidly to forest habitat without the presence of deer. Some fields abandoned for 10 to 15 years showed significant invasion by early successional trees such as aspen and birch. Some aspens in these fields had already attained heights of 3 to $6 \mathrm{~m}$.

\section{DISCUSSION}

\section{Population Dynamics}

\section{Population Buildups and Dieoffs}

Deer herd fluctuations on NMI between 1977 and 1982 are illustrated in figure 12 . At minimum, 1,393 deer were present in the fall of 1977, based on the known harvest of 511 and the estimated winter mortality of 882. Population estimates were not available for 1978 and 1979, but winter mortalities in 1978-79 and 1979-80 were estimated at 81 and 186, respectively. The low mortality estimates for the severe 1978-79 winter reflected a relatively low prehunt population in 1978.

By the spring of 1980 , the population had increased to 873 . From that prefawn population, the deer increased 66 percent to a prehunt population of 1,447 , despite moderate winter mortality in 1979-80. In 1981, the population increased by 59 percent from the prefawn 1,308 to a prehunt size of 2,080. The 1981 prehunt population was reduced by 76 percent by severe weather conditions in the winter of 1981-82. The prefawn 1982 population was relatively low, with probably fewer than 500 deer.

The rates of increase observed in 1980 and 1981 are some of the highest reported for white-tailed deer. Gross (1969) reported a maximum rate of increase of 60 percent for deer on the George Reserve. Examination of that case in greater detail (McCullough $1982 b, 1983$; Eberhardt 1985) showed rates of increase that averaged 76 and 66 percent per year over two different growth periods. The highest percentage increase observed in any year on Rachelwood, Pennsylvania (Woolf and Harder 1979) was 52 percent. Palmer and King (1970) estimated the yearly population growth for 1969 on South Fox Island to be about 70 percent. The South Fox Island herd was expanding and the herd and habitat were in excellent condition at the time. It was particularly interesting to observe such a large increase in the NMI herd in 1980, considering the poor condition of the habitat. The adult sex ratio strongly favored females and the prefawn herd age structure was heavily skewed toward the prime age females. Together, these factors contributed to high herd productivity.

Verme $(1965 b)$ reported that does eating a generous versus a restricted diet during the rutting period produced significantly more fawns the following spring. The fall 1979 diet was good on NMI because preferred foods such as fruits, acorns, and grasses were abundant.

Nutrition in the final third of gestation was found by Verme (1962) to be critically important for proper fetal development. He showed that does that were underfed in winter and then switched to a high or low spring nutritional level differed significantly in reproductive success. Again, spring nutrition on NMI was considered good because of an abundance of lush spring ephemerals and grasses. An additional source of nutrition during the spring is the alewife dieoff (Case and McCullough 1987). The combined 


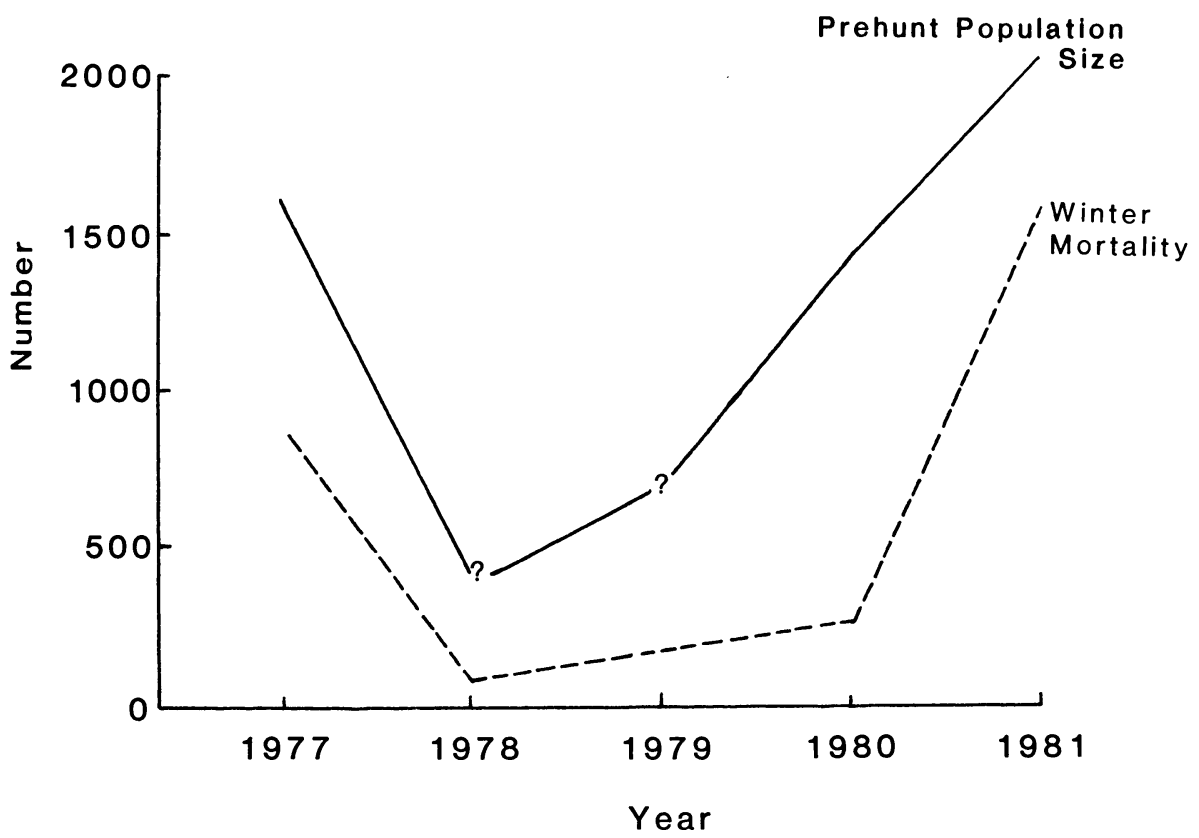

Fig. 12. White-tailed deer prehunt population size, and winter mortality, 1977 to 1981.

high nutrient and sodium intake obtained from foraging on alewives may have been an important contributor to the high herd productivity.

It appears, then, that although the deer range on NMI was overbrowsed and in poor condition overall, the abundance of high-quality food sources during critical periods contributed to the relatively high observed reproductive rates. Mild winters and early springs in 1980 and 1981 also contributed to the high reproductive rates. The severity of the winter affects the condition of females prior to parturition (Verme 1962, 1963). The early arrival of spring gave the does a longer period of good nutrition before parturition, and that may have increased fawn survival.

We anticipate that no equilibrium will be achieved between habitat and deer on NMI. McCullough (1979) demonstrated the inability of the white-tailed deer to avoid habitat destruction. He suggested that only in situations where the environment was stable and predictable, where predator populations were high, or where humans intelligently intervened could a stable balance be expected.

For deer in northern regions, winter is the critical period for survival. Winters, in turn, are quite variable in intensity and duration and are not predictable. The summer range on NMI can support a much higher population than the winter range-browse plants have been highlined, plant species composition has shifted toward unpalatable species, and there is no good closed-canopy yarding area to afford thermal cover. Hence, deer on NMI can be expected to suffer substantial mortality from thermal stress and 
starvation during severe winters. According to dead deer surveys, 18 percent of the 1980 prehunt population died due to winter thermal stress and starvation. If the prehunt 1980 and prefawn 1981 population sizes computed by the Kelker method are compared, 10 percent of the prehunt population can be said to have succumbed to winter mortality. According to dead deer surveys conducted in May 1982, 76 percent of the 1981 prehunt population died over the winter. The relatively small prefawn population expected in 1982 was substantiated during dead deer surveys in May 1982.

Pronounced oscillations in population size on NMI can be expected to continue in the future. Populations will be reduced in severe winters, but will rapidly increase again until another severe winter brings the population back down. The sex and age structure of the herd and the condition of the habitat in the spring of 1982 were similar to conditions in the spring of 1978. On the basis of these observations, we expect that the deer herd on NMI, in the absence of harvesting, will again increase in size until winter conditions result in a decline.

This pattern can be broken with the management tool of hunting. Liberal hunting seasons will stabilize the deer population at moderately low levels and result in animals that are in better shape to withstand winter conditions. With fewer deer, the island will regenerate a more palatable mix of woody browse species, and better winter browse will improve winter conditions, despite the lack of good thermal cover. Because favorable spring-through-fall forage conditions foster rapid population growth, continued liberal hunting seasons will be necessary to contain the population within acceptable limits.

\section{Differential Winter Mortality}

The sex and age structures of the NMI deer herd during the period of study were similar to those of other deer herds on overstocked ranges (Gunvalson, Erickson, and Burkalow 1952; Klein and Olson 1960; Jensen 1982). Klein (1970) stated that the older animals dominated deer herds in which food had become a limiting factor because of high deer densities or other conditions. He listed three factors that contributed to this dominance: (1) age of sexual maturity is delayed; (2) fertility is lowered; and (3) fawn survival is decreased.

The age of sexual maturity for NMI does was delayed because few if any fawns bred. The reproductive rates of NMI does were higher than would be expected, but as mentioned, comparisons were complicated by the lack of age-specific data. Fawn survival to 1 year of age was low due to winter starvation. Klein's three factors were all observed in the NMI herd.

The change in the age structure of male winter mortality from year to year reflected differences in the severity of the corresponding winters. The harsher the winter, the larger the proportion of older deer in the dieoff. Fawns sustained substantial mortality in all winters, even mild ones, due to their small physical size and poor condition.

There was a significant difference $(P<0.001)$ in dead deer age structure between years. In the winters of 1977-78, 1979-80, and 1980-81, more fawns and fewer yearlings died than would have been expected. This structure was reversed in 1981-82, when we found fewer fawns and more yearlings dead.

The winters of 1977-78 and 1978-79 were considered severe in terms of deer survival in northern Michigan (Burgoyne and Moss 1979). Fawns made up 77.0 and 79.4 percent of the discovered mortality, respectively. The winters of $1979-80$ and $1980-81$, on the other hand, were quite mild, and fawns made up 89.7 and 88.7 
percent of the discovered mortality. The winter of 1981-82 was the harshest winter of the five, and fawns made up only 54.6 percent of the mortality.

Klein and Olson (1960) reported an age structure of starvation losses of sitka deer (Odocoileus bemionus sitkensis) in Alaska similar to the structures shown in this study. They found mortality rates to be highest among the fawn and old age classes, while prime-aged deer, between 1.5 and 5.5 years, accounted for less than 10 percent of the starvation losses. The age structure of winter mortality was also similar in the Beaver Basin deer population (Jensen 1982). Fawns ranged from 47.8 to 84.6 percent of the discovered mortality over a 6-year period. The age structure of deer winter mortality on NMI was different than that found on Rachelwood Preserve, where Woolf and Harder (1979) detected no difference from year to year in the age structure of mortality. It may be that the less severe winters or the extensive winter feeding program on Rachelwood resulted in a more stable mortality structure and rate.

Mortality of adult males ( 1.5 years and older) was quite low in mild winters (1979-80 and 1980-81), and consequently constituted a much smaller proportion of the measured mortality. The same trend was evident for female mortality (table 16), but the differences were not significant $(P>0.05)$. Heavy winter starvation losses, the major mortality factor in the NMI herd and in other herds on overstocked ranges, seems to result in a preponderance of adult females, since males are more susceptible to mortality.

That males are more susceptible to winter mortality than females has been reported in both hunted and unhunted populations (Gunvalson, Erickson, and Burkalow 1952; Robinette et al. 1957; Klein and Olson 1960; Woolf and Harder 1979; Jensen 1982). Woolf and Harder (1979) presented three hypotheses to account for the differential winter mortality of male white-tailed deer on the Rachelwood Preserve. The first hypothesis was that enterotoxemia (a disease caused by overingestion of acorns) affected males more than females. It is doubtful that enterotoxemia was a significant mortality factor on NMI. Oak forests account for less than 10 percent of the habitat on NMI, compared to 54 percent on Rachelwood. Furthermore, only one of the eighty-two 1.5-year-or-older male carcasses located had not cast its antlers. Any deer succumbing to enterotoxemia would have done so in the fall of the year when antlers were still present. The one antlered carcass we located was thought to have been killed by poachers.

The second hypothesis was that males were more susceptible to hunter-induced crippling loss than were females. Because hunting was conducted prior to the winter of $1977-78$, crippling loss could have been a factor. Hunting was not conducted after that time, but males were still more susceptible to winter mortality.

The third hypothesis was that the overwinter weight loss of males might contribute to greater mortality. The deer on both NMI and Rachelwood were considered to be in poor physical condition. If males have a tendency to lose more weight than females, it is possible they would reach the critical 30 percent weight loss (deCalesta, Nagy, and Bailey 1975) more quickly than females.

Klein and Olson (1960) hypothesized that the physiological drain of rutting activities in the fall could cause males to be in poorer physical condition than females at the onset of winter. Adult males expend considerable energy during the rut. In addition to increased activity, adult males feed less when rutting, resulting in a loss of body weight due to fat mobilization (McCullough 1979; White 1968). This loss of weight could be critical for males on overbrowsed range, in that sufficient food may not be available to replenish fat reserves prior to winter. 
Verme $(1962,1965 b)$ showed that the prewinter physical condition of does that nursed fawns may be poorer than that of barren does. Because a sizable proportion of the adult (including yearling) does on NMI may have been barren in a given year, the female segment of the population may have been in better physical condition than the male segment at the onset of winter.

Verme $(1965 b, 1969,1983)$ demonstrated the uneven sex ratio toward males as habitat conditions worsened, and postulated that this serves as a population selfregulating mechanism. Critical to this postulate is the assumption of equal survivability between the sexes. Our study and others have shown that males are considerably more susceptible to mortality than are females in herds existing under poor range conditions. Hence, a sex ratio that favored males at birth would not persist as that cohort reached prime reproductive age, because of differential mortality among fawns.

\section{Parasites and Density}

Wildlife managers have long held that parasite burdens in wildlife populations are density-dependent (Leopold 1933; Klein 1970; Woolf and Harder 1979; Eve and Kellogg 1977). The deer on NMI had a high herd density and existed under poor habitat conditions, yet they had low parasite burdens relative to the more healthy, less dense mainland herd. Eve and Kellogg (1977) found a significant correlation between abomasal parasite burdens and deer density in white-tailed deer in the southeastern United States. Deer on the Rachelwood Preserve (Woolf and Harder 1979) were considered in poor physical condition on the basis of herd parameters such as body weight and reproductive performance, but had low parasite burdens. Woolf and Harder (1979) concluded that their results from the Rachelwood study contrasted with those of Eve and Kellogg. Stuht (1980) found no relationship between deer density and parasitism in Michigan deer, but found a significant correlation between parasitism and forest type. It appears that there are exceptions to the relationship between parasite burdens and general herd condition and density in northern deer ranges.

\section{Habitat Relationships}

\section{Impact of Deer on Succession}

In 1979, initial reconnaissance of NMI by the authors indicated the island was severely overbrowsed by deer. A pronounced browse line was obvious in all habitat types, and production of deciduous and coniferous trees and shrubs except beech was scarce. Vegetation surveys conducted in 1980 and 1981 documented the impact of deer on vegetation.

Old-field succession on the island had been halted or at least reduced to a very slow rate. In terms of deer nutrition, this is beneficial in that forbs and grasses remained abundant. Graminids were an important food source during all seasons, but may have been more important in winter and spring to deer on NMI than in other areas because of the lack of woody browse. Our observations of deer and deer sign in January and February of 1981 and 1982 indicated that deer were pawing through the snow cover and feeding on dried grasses, forbs, and deciduous leaves. Hubert (1974) and Harlow et al. (1975) found that dry, fallen leaves were important in the winter diet of deer, 
especially during periods of mast scarcity. Watts (1964) found that deer even preferred dried leaves to woody browse during the winter.

Observations of feeding deer on NMI indicated that they relied heavily on woodland ephemerals and graminids as spring food sources. Summer foods of NMI deer, in addition to graminids, consisted of forbs and the seedlings of woody trees and shrubs. Important foods included spotted knapweed, sheep sorrel (Rumex acetosella), and ferns. Sugar maple was the most important woody seedling. In the fall, a large portion of the diet consisted of apple fruit, and lesser portions consisted of acorns and beechnuts. The leaves of sugar maple and cherry were also heavily browsed.

\section{Impact of Deer on Plant Species Composition}

The impact of deer on forest vegetation has been to the detriment of the deer herd. In areas where the forest canopy has been opened by timber harvesting, deer have selectively removed preferred browse species, allowing less palatable beech to dominate the deciduous reproduction. Beech was by far the dominant browse species available on NMI, and browse production by other species was nearly absent. White-tailed deer on NMI and in other areas (Webb, King, and Patric 1956; Hough 1965; Marquis and Brenneman 1981) rarely consume beech even when the browse of preferred species is in short supply.

Deer overbrowsing has significantly hindered the reproduction of preferred evergreen foods such as northern white cedar and white pine, and has apparently extirpated ground hemlock (yew) from the island. The reduction of important winter foods, especially ground hemlock and northern white cedar, has resulted in a concomitant reduction in winter carrying capacity.

Ground hemlock, a highly preferred winter food for deer, was conspicuously absent from NMI. Ground hemlock is a common understory shrub on nearby South Manitou and South Fox islands and on the adjacent mainland. Ground hemlock constituted 88.3 and 97.9 percent of the winter diet of deer on Garden and South Fox islands, respectively (King 1970). Beals, Cottam, and Vogl (1960) compared vegetation that had been subjected to varying degrees of deer browsing on the Apostle Islands in Lake Superior. They found that ground hemlock was sensitive to deer utilization and that it began to disappear even under moderate browsing. Under heavy browsing, ground hemlock was completely eliminated. King (1970) reported similar results on Garden and South Fox islands.

We believe the absence of ground hemlock from NMI is a result of severe deer browsing. Deer browsing has nearly eliminated the reproduction of preferred browse species such as northern white cedar, white pine, and sugar maple on NMI, but all preferred browse species are still relatively abundant in the overstory. Ground hemlock, a low-growing species, does not appear to be present at all on NMI.

Deer foraging also affected aquatic vegetation, particularly along the Lake Manitou shoreline. Deer foraged on aquatic vegetation throughout late spring, summer, and early fall. Along portions of the Lake Manitou shoreline where emergent vegetation was abundant, a definite feeding line was apparent in 1980 and 1981 where water depth prohibited further deer feeding. Deer not only browsed the emergent portions of plants; they were also observed pulling up plants by the roots.

Although the results obtained on NMI represent an extreme case of prolonged overbrowsing and overpopulation, they illustrate the potential of white-tailed deer to 
influence forest vegetation. Anderson and Loucks (1979) assessed the effects of heavy and light deer browsing on the composition and structure of eastern hemlock forests in northern Wisconsin, and found that sugar maple replaced hemlock in areas that were heavily browsed by deer. They concluded that high deer populations could have a substantial impact on the reproduction of different tree species, and, consequently, on species composition of the mature forests in the Lake States region.

Similarly, Marquis (1981) found that high deer populations over several decades had resulted in the complete elimination of understory vegetation in uncut northern hardwoods stands on the Allegheny Plateau of Pennsylvania. In areas that did regenerate, he found that preferential browsing by deer nearly eliminated sugar maple, red maple, black cherry (Prunus serotina), Rubus spp., and northern red oak (Quercus rubra), and allowed the sites to be taken over by beech and striped maple (Acer pennsylvanicum). Webb, King, and Patric (1956) reported that deer browsing on forest vegetation in the Adirondacks of New York reduced the height and diameter of new sugar maples. In that case, deer activity resulted in the establishment of more beech than would have been expected had there been no browsing.

Besides affecting the composition of vegetation in northern hardwood forests, deer browsing can result in economic losses in the form of reduced timber production. Marquis (1981) estimated the annual loss from deer damage to the Allegheny Plateau was at least $\$ 13$ per acre.

Deer will continue to affect the vegetation on NMI as long as the size of the herd is determined by winter mortality. If the deer population is reduced and then maintained at a low level by hunting or other human intervention, changes in the structure and composition of the vegetation on the island could be expected. Old fields would eventually succeed to forest. The rate of this succession would depend on deer density as well as such environmental factors as soil type and the availability of seed sources.

In the mature hardwood forest type, an understory typical of that habitat would probably develop. The degree to which species other than beech would be able to invade in areas that have been selectively cut is unknown, but beech would probably remain dominant. The changes brought about by 40 years' deer overpopulation on NMI will be evident for many years, even if managers achieve effective deer herd control. 


\section{ACKNOWLEDGMENTS}

This study was supported by the United States Department of the Interior, National Park Service, under contract number CX-6000-8R174 to Dale R. McCullough. The research was administered through the University of Michigan, School of Natural Resources.

Sleeping Bear Dunes National Lakeshore provided logistical support throughout the study. In particular, the authors would like to thank Superintendent R. Peterson and staff members $M$. Holden and S. Yancho for their significant contributions of time and energy to this project. Personnel of the Michigan Department of Natural Resources, including J. Stuht, R. Huff, and R. Odum, provided various kinds of assistance. The Michigan Department of Natural Resources Wildlife Pathology Laboratory analyzed mandibular fat levels and provided the results of the parasite examinations. A. Reznicek identified unknown plant samples from deer rumina.

The Grosvenor family, owners and operators of Manitou Island Transit, provided dependable mail and grocery deliveries. Their open door and warm hospitality toward researchers stranded on the mainland were greatly appreciated. Ken and Rita Rusco, the last island residents, courteously shared their knowledge of the island and its history and helped researchers adjust to island life. The assistance of J. Clement, D. L. Case, S. Fogle, R. Fahlsing, G. Wiles, A. Parker, H. Swaney, E. Swaney, and T. Clement in conducting field work is gratefully acknowledged. We also extend special thanks to Ronald and Sharon Case, parents of the senior author, who supported this research in many ways.

Thanks also to R. Drobney, who served as academic advisor for D. J. Case and reviewed drafts of the manuscript; to G. Belovsky for editorial assistance and the use of laboratory facilities; and to D. Rabe who kindly offered the use of his laboratory and office space. 


\section{LITERATURE CITED}

ANDERSON, D. R., and R. S. POSPAHALA

1970. Correction of bias in belt transect studies of immotile objects. J. Wildl. Manage. 34(1):141-46.

ANDERSON, R. C., and O. C. LOUCKS

1979. White-tailed deer influence on structure and composition of Tsuga canadensis forests. J. Appl. Ecol. 16(3):855-61.

ARNOLD, D. A.

1970. Winter feeding of game-An ignored management tool? Michigan Dep. Nat. Resour. Info. Circ. No. 177. 7 pp.

ARNOLD, D. A., and I. H. BARTLETT

1968. North Manitou Island Deer. Michigan Dep. Conserv. Game Div., Report No. 6267. 13 pp.

BEALS, E., G. COTTAM, and R. VOGL

1960. Influence of deer on vegetation of the Apostle Islands, Wisconsin. J. Wildl. Manage. 24(1):66-80.

BELOVSKY, G. E.

1978. The time-energy budget of a moose. Theor. Pop. Bio. 14(1):76-104.

BEIER, $\mathrm{P}$.

1987. Sex differences in quality of white-tailed deer diets. J. Mammal. 68(2):323-29.

BURGOYNE, G. E., JR., J. MEISTER, and M. ALEXANDER

1981. Deer checking station data-1980. Michigan Dep. Nat. Resour. Wildl. Div. Report No. 2888. 36 pp.

BURGOYNE, G. E., JR., and M. L. MOSS

1979. Estimated winter deer losses in Michigan 1978-79. Michigan Dep. Nat. Resour., Surveys Stat. Serv. Report No. 187. 10 pp.

1981. The 1981 deer pellet group surveys. Michigan Dep. Nat. Resour. Wildl. Div. Report No. 2898. 19 pp.

BURNHAM, K. P., and D. R. ANDERSON

1976. Mathematical models for nonparametric inferences from line transect data. Biometrics 32(2):325-36.

CASE, D. J.

1982. The white-tailed deer of North Manitou Island, Michigan. M.S. thesis, Univ. Michigan, Ann Arbor. 166 pp.

CASE, D. J., and D. R. MCCULLOUGH

1987. White-tailed deer forage on alewives. J. Mammal. 68(1):195-97.

CASE, D. J., and W. C. SCHARF

1985. Additions to the birds and land vertebrates of North Manitou Island. Jack-Pine Warbler 63(1):17-23.

CAUGHLEY, G.

1977. Analysis of vertebrate populations. John Wiley and Sons, London.

CHAMRAD, A. D., and T. W. BOX

1964. A point-frame for sampling rumen contents. J. Wildl. Manage. 28(3):473-77.

CHEATUM, E. L.

1949. Bone marrow as an index of malnutrition in deer. N. Y. State Conserv. 3(1):29-32.

COBLENTZ, B. E.

1970. Food habits of George Reserve deer. J. Wildl. Manage. 34(3):535-40.

COE, R. J., R. L. DOWNING, and B. S. MCGINNES

1980. Sex and age bias in hunter-killed white-tailed deer. J. Wildl. Manage. 44(1):245-49.

COLLINS, W. B., and P. J. URNESS

1981. Habitat preferences of mule deer as rated by pellet-group distribution. J. Wildl. Manage. 45(4):969-71.

DECALESTA, D. S., J. G. NAGY, and J. A. BAILEY

1975. Starving and refeeding mule deer. J. Wildl. Manage. 39(4):663-69.

DOWNING, R. L., E. D. MICHAEL, and R. J. POUX, JR.

1977. Accuracy of sex and age ratio counts of white-tailed deer. J. Wildl. Manage. 41(4):709-14.

DUVENDECK, J. P.

1968. The 1967 deer season Bois Blanc and Beaver Islands. Michigan Dep. Conserv. Res. Dev. Report No. 134. 20 pp.

EBERHARDT, L. L.

1968. A preliminary appraisal of line transects. J. Wildl. Manage. 32(1):1-31.

1985. Assessing the dynamics of wild populations. J. Wildl. Manage. 49(4):997-1012.

EVE, J. H., and F. E. KELLOGG

1977. Management implications of abomasal parasites in southeastern white-tailed deer. J. Wildl. Manage. 41(2):169-77.

FRIEDRICH, P. D., and G. E. BURGOYNE, JR.

1980. Correlation of wet weight, dry weight, and fat levels in bone marrow from white-tailed deer. Michigan Dep. Nat. Resour. Wildl. Div. Report No. 2856. 4 pp. 
GATES, C. E., W. H. MARSHALL, and D. P. OLSON

1968. Line transect method of estimating grouse population densities. Biometrics 24:135-145.

GROSS, J. E.

1969. Optimum yield in deer and elk populations. Trans. N. Am. Wildl. Conf. 34:372-85.

GUNVALSON, V. E., A. B. ERICKSON, and D. W. BURKALOW

1952. Hunting season statistics as an index to range conditions and deer population fluctuations in Minnesota. J. Wildl. Manage. 16(2):121-31.

HARDER, J. D.

1980. Reproduction of white-tailed deer in the north central United States. In White-tailed deer population management in the north central states, eds. R. L. Hine and S. Nehls, 23-35. Proc. 1979 Symp. North Cent. Sect. Wildl. Soc.

HARLOW, R. F., J. B. WHELAN, H. S. CRAWFORD, and J. E. SKEEN

1975. Deer foods during years of oak mast abundance and scarcity. J. Wildl. Manage. 39(2):303-36.

HATT, R. T., J. VANTYNE, L. C. STUART, C. H. POPE, and A. B. GROBMAN

1948. Island Life: A study of the land vertebrates of the islands of eastern Lake Michigan. Cranbrook Inst. Sci. Bull. 27:1-179.

HESSELTON, W. T., and P. R. SAUER

1973. Comparative physical condition of four deer herds in New York according to several indices. N.Y. Fish Game J. 20(2):77-107.

HIRTH, D. H.

1977. Social behavior of white-tailed deer in relation to habitat. Wildl. Monogr. No. 53.55 pp. HOUGH, A. F.

1965. A 20-year record of understory vegetation change in a virgin Pennsylvania forest. Ecology $46(3): 370-73$.

HUBERT, G. R., JR

1974. Food habits of a large, confined white-tailed deer herd provided with supplemental feed. M.S. thesis, Colorado State Univ., Fort Collins. 181 pp.

JENSEN, W. F.

1982. Vegetation analysis and an analytical model of the Beaver Basin deer yard. M.S. thesis, Northern Michigan Univ., Marquette. 156 pp.

KARNS, P. D.

1980. Winter - the grim reaper. In White-tailed deer population management in the north central states, eds. R. L. Hine and S. Nehls, 47-53. Proc. 1979 Symp. North Cent. Sect. Wildl. Soc.

KELKER, G. H.

1945. Measurement and interpretation of forces that determine populations of managed deer. Ph.D. thesis, Univ. Michigan, Ann Arbor. 422 pp.

KING, D. R.

1970. Deer and hare population range relationships on Garden and South Fox islands, Michigan. Ph.D. thesis, Univ. of Michigan, Ann Arbor. 228 pp.

KIRKPATRICK, C. M., C. M. WHITE, T. W. HOEKSTRA, F. A. STORMER, and H. P. WEEKS

1976. White-tailed deer of U.S. Naval Ammunition Depot Crane. Purdue Univ. Agric. Exp. Stn.

KLEIN, D. R Res. Bull. No. 932.42 pp.

1970. Food selection by North American deer and their response to overutilization of preferred plant species. In Animal populations in relation to their food resources, ed. A. Watson, 25-46. British Ecol. Soc. Symp. 10, Blackwell, Edinburgh.

KLEIN, D. R., and S. T. OLSON

1960. Natural mortality patterns of deer in southeast Alaska. J. Wildl. Manage. 24(1):80-88.

LEOPOLD, A.

1933. Game management. Charles Scribner's Sons, New York. 481 pp.

MARQUIS, D. A.

1981. The effect of deer browsing on timber production in Allegheny hardwood forests of northwestern Pennsylvania. Northeast For. Exp. Stn., Broomall, Pa. 10 pp.

MARQUIS, D. A., and R. BRENNEMAN

1981: The impact of deer on forest vegetation in Pennsylvania. Northeast For. Exp. Stn., Broomall, Pa. 7 pp.

MCCAFFERY, K. R., J. TRANETZKI, and J. PIECHURA, JR.

1974. Summer foods of deer in northern Wisconsin. J. Wildl. Manage. 38(2):215-19.

MCCULLOUGH, D. R.

1979. The George Reserve deer herd: Population ecology of a K-selected species. Univ. Michigan Press, Ann Arbor. 271 pp.

1982a. Evaluation of night spotlighting as a deer study technique. J. Wildl. Manage. 46(4):715-38.

1982b. Population growth rate of the George Reserve deer herd. J. Wildl. Manage. 46(4):1079-83.

1983. Rate of increase of white-tailed deer on the George Reserve: A response. J. Wildl. Manage. 47(4):1248-50.

1985. Variables influencing food habits of white-tailed deer on the George Reserve. J. Mammal. 66(4):682-92. 
NEFF, D. J.

1968. The pellet-group count technique for big game trend, census, and distribution: A review. J. Wildl. Manage. 32(4):597-614.

NELSON, M. E., and L. D. MECH

1981. Deer social organization and wolf predation in northeastern Minnesota. Wildl. Monogr. No. 77. $53 \mathrm{pp}$.

OZOGA, J. J., and L. W. GYSEL

1972. Response of white-tailed deer to winter weather. J. Wildl. Manage. 36(3):892-96.

PALMER, W. L., and D. R. KING

1970. South Fox Island deer-1969. Michigan Dep. Nat. Resour. Dev. Report No. 204. 10 pp.

PUGLISI, M. J., S. A. LISCINSKY, and R. F. HARLOW

1978. An improved methodology of rumen content analysis of white-tailed deer. J. Wildl. Manage. 42(2):397-403.

RINEY, T.

1955. Evaluating condition of free-ranging red deer Cervus elaphus, with special reference to New Zealand. N. Z. J. Sci. Technol. 36(5):429-63.

ROBEL, R. J., and P. G. WATT

1970. Comparison of volumetric and point-analysis procedures to describe deer food habits. J. Wildl. Manage. 34(1):210-13.

ROBINETTE, W. L., J. S. GASHWILER, J. B. LOW, and D. A. JONES

1957. Differential mortality by sex and age among mule deer. J. Wildl. Manage. 21(1):1-16.

ROBINSON, W. L., L. H. FANTER, A. G. SPALDING, S. L. JONES, and W. F. JENSEN

1982. Deer of Beaver Basin: Ecology and management of a man-made eruption. Progress report, National Park Service. 47 pp.

ROGERS, J. H.

1973. South Manitou Island. Northwestern Michigan College, Traverse City, Michigan. 31 pp.

SCHARF, W. C., and M. L. JORAE

1980. Birds and land vertebrates of North Manitou Island. Jack-Pine Warbler 58(1):4-15.

SEN, A. R., J. TOVRIGNY, and G. E. J. SMITH

1974. On the line transect sampling method. Biometrics 30(2):329-40.

SEVERINGHAUS, C. W.

1949. Tooth development and wear as criteria of age in white-tailed deer. J. Wildl. Manage. 13(2): 195-216.

STORMER, F. A., and W. A. BAUER

1980. Summer forage use by tame deer in northern Michigan. J. Wildl. Manage. 44(1):98-106.

STUHT, J. N.

1980. Ecological aspects of parasitism in white-tailed deer. Michigan Dep. Nat. Resour. Wildl. Div. Report No. 2855. 23 pp.

TABER, R. D., and R. F. DASMANN

1954. A sex difference in mortality in young Columbian black-tailed deer. J. Wildl. Manage. 18(3):309-15.

TEER, J. G., J. W. THOMAS, and E. A. WALKER

1965. Ecology and management of white-tailed deer in the Llano Basin of Texas. Wildl. Monogr. 15:1-62.

ULLREY, D. E., W. G. YOUATT, H. E. JOHNSON, L. D. FAY, B. E. BRENT, and K. E. KEMP

1968. Digestibility of cedar and balsam fir browse for the white-tailed deer. J. Wildl. Manage. 32(1):162-71.

VERME, L. J.

1962. Mortality of white-tailed deer fawns in relation to nutrition. Natl. Deer Disease Symp. Proc. $1: 15-38$.

1963. Effects of nutrition on growth of white-tailed deer fawns. Trans. N. Am. Wildl. Conf 28:431-43.

1965a. Swamp conifer deer yards in northern Michigan, their ecology and management. J. For. 63(7):523-29.

1965b. Reproduction studies on penned white-tailed deer. J. Wildl. Manage. 29(1):74-79.

1969. Reproductive patterns of white-tailed deer related to nutritional plane. J. Wildl. Manage. 33(4):881-87.

1973. Movements of white-tailed deer in upper Michigan. J. Wildl. Manage. 37(4):545-52.

1983. Sex ratio variation in Odocoileus: A critical review. J. Wildl. Manage. 47(3):573-82.

WARREN, R. J., R. L. KIRKPATRICK, A. OELSCHLAEGER, P. F. SCANLON, and

F. C. GWAZDAUSKAS

1981. Dietary and seasonal influences on nutritional indices of adult male white-tailed deer. J. Wildl. Manage. 45(4):926-36.

WATTS, R. C.

1964. Forage preferences of captive deer while free ranging in a mixed oak forest. M.S. thesis. Pennsylvania State Univ. 104 pp. 
WEBB, W. L., R. T. KING, and E. F. PATRIC

1956. Effect of white-tailed deer on a mature northern hardwood forest. J. For. 54(6):391-98. WEBER, L. H.

1973. Soil Survey of Leelanau County, Michigan. U.S. Dep. Agric. Soil Conserv. Serv. 90 pp.

WHITE, D. L.

1968. Condition and productivity of New Hampshire deer. In The white-tailed deer of New Hampshire, ed. H. R. Siegler, 69-113. Survey Rep. No. 10. New Hampshire Fish Game Dep., Concord. 256 pp.

WOOLF, A., and J. D. HARDER

1979. Population dynamics of a captive white-tailed deer herd with emphasis on reproduction and mortality. Wildl. Monogr. No. 67. 53 pp.

The University of California, in compliance with the Civil Rights Act of 1964, Title IX of the Educational Amendments of 1972, and the Rehabilitation Act of 1973, does not discriminate on the basis of race, creed, religion, color, national origin, sex, or mental or physical handicap in any of its programs or activities, or with respect to any of its employment policies, practices, or procedures. The University of California does not discriminate on the basis of age, ancestry, sexual orientation, marital status, citizenship, medical condition (as defined in section 12926 of the California Government Code), nor because individuals are disabled or Vietnam era veterans. Inquiries regarding this policy may be directed to the Personnel Studies and Affirmative Action Manager, Division of Agriculture and Natural Resources, 2120 University Avenue, University of California, Berkeley, California 94720, (415) 644-4270. 


\section{HILGARDIA Editorial Board}

\section{Edward S. Sylvester, Chairman, Berkeley}

(entomology, insecticides, ecology, environmental toxicology)

Peter Berck, Associate Editor, Berkeley (economics, statistics, resource management)

Harry W. Colvin, Associate Editor, Davis (animal science, physiology, breeding, zoology, genetics)

Donald J. Durzan, Associate Editor, Davis (tree fruit and nut crops)

Walter G. Jennings, Associate Editor, Davis

(food science, nutrition, and chemistry)

John Letey, Associate Editor, Riverside (soils, plant nutrition, agronomy, agricultural engineering, water)

(field and row crops)

Irwin P. Ting, Associate Editor, Riverside (botany, plant physiology, biochemistry)

Richard V. Venne, Managing Editor, Berkeley

The Journal HILGARDIA is published irregularly. Number of pages and number of issues vary per annually numbered volume. Address: Agriculture and Natural Resources Publications, University of California, Berkeley, CA 94720. 